\title{
Experimental Investigation of a Thermally Powered Central Heating Circulator: Pumping Characteristics
}

\author{
Christos N. Markides*, Ajay Gupta \\ Clean Energy Processes Laboratory \\ Department of Chemical Engineering, Imperial College London, London, SW7 2AZ, U.K.
}

Corresponding author: c.markides@imperial.ac.uk; +44 2075941601

\begin{abstract}
A thermally powered circulator based on a two-phase thermofluidic oscillator was constructed and operated successfully as a replacement for a central heating hot water circulator coupled to a domestic gas-fired boiler. During regular operation the thermally powered circulator demonstrated a pumped flow-rate that decreased monotonically as the head applied across it increased. A maximum measured flow-rate of $850 \mathrm{~L} / \mathrm{hr}$ was achieved at zero head, and a maximum head of $8.4 \mathrm{mH}_{2} \mathrm{O}$ was attained at near-stalling (zero flow-rate) conditions. In agreement with previous modelling studies of the technology, increased inertia in the load line seems to lead to improved circulator performance. The maximum pumped flow-rates were achieved at medium to high $10-15 \mathrm{~kW}$ boiler heat settings, and the maximum heads at medium 10-12 kW heat settings. It was also found that the increased introduction of heat into the circulator led generally to greater flow-rates, until a certain level, and that the internal temperature difference across the working fluid (water/steam) within the circulator showed a positive correlation with its maximum head capability. In both cases a limit was reached beyond which the performance of the circulator could not be improved further. The pumped flow-rates demonstrated indicate that the technology is capable of achieving a realistic pumping performance for this application, though the deterioration of the flow-rates at the higher loads (heads), as would be experienced in real central heating flow circuits, will need to be addressed. Further, the oscillating circulator exhibited an operational frequency between 0.24 and $0.33 \mathrm{~Hz}$, which was mostly determined by the circulator configuration. The pumping capacity was strongly affected by the oscillating liquid amplitudes in the power cylinder that defined the positive displacement amplitudes of the liquid piston into and out of the hot water circuit. The best circulator configuration was associated with lower operation frequencies and relatively large ratios of suction to discharge displacement.
\end{abstract}


Keywords: energy efficiency; low-grade heat; heat engine; thermofluidic oscillator; central heating circulator; thermally powered pump 


\section{NOMENCLATURE}

$\begin{array}{ll}\text { Abbreviation } & \\ \text { NIFTE } & \text { Non-Inertive-Feedback Thermofluidic Engine } \\ \text { TPC } & \text { Central Heating } \\ \text { HHX } & \text { Thermally Powered Circulator } \\ \text { CHX } & \text { Hot Heat Exchanger } \\ \text { PTL } & \text { Power Transmission Line } \\ \text { HP } & \text { High Pressure } \\ \text { LP } & \text { Low Pressure } \\ \text { TC- } & \text { Thermocouple } \\ \text { T- } & \text { Temperature Dials } \\ \text { HPR } & \text { High Pressure Reservoir } \\ \text { LPR } & \text { Low Pressure Reservoir } \\ \text { DAQ } & \text { Data Acquisition } \\ \text { SC } & \text { Signal Conditioning } \\ \text { PG } & \text { Pressure Gauge } \\ \text { rms } & \text { Root Mean Square }\end{array}$

Symbols

$U \quad$ Flow-rate in the TPC hydraulic circuit [L/hr]

$U_{\mathrm{e}} \quad$ Flow-rate in the $\mathrm{CH}$ hydraulic circuit $[\mathrm{L} / \mathrm{hr}]$

$U_{0} \quad$ Maximum flow-rate in the TPC circuit at zero head conditions [ $\left.\mathrm{L} / \mathrm{hr}\right]$

$\triangle P \quad$ Pressure difference across the TPC $\left[\mathrm{mH}_{2} \mathrm{O}\right]$

Time-averaged $\Delta P$ across the TPC $\left[\mathrm{mH}_{2} \mathrm{O}\right]$

$\Delta P_{\max } \quad$ Maximum $\triangle P$ across the TPC at near-stalling conditions $\left[\mathrm{mH}_{2} \mathrm{O}\right]$

$Q_{\text {boil }} \quad$ Heat from the flame generated by burning natural gas in the boiler [W]

$Q_{H, \text { loss }} \quad$ Heat losses from the boiler faceplate based on direct measurements [W]

$Q_{H H X} \quad$ Heat supplied to the HHX [W]

$Q_{\mathrm{CH}} \quad$ Heat supplied to the $\mathrm{CH}$ circuit [W]

$L_{\mathrm{PTL}} \quad$ Length of the PTL $[\mathrm{m}]$

$T_{\text {HHX-fluid }} \quad$ Temperature of the steam at the top of the power cylinder at the moment of evaporation within the $\mathrm{HHX}\left[{ }^{\circ} \mathrm{C}\right.$ or $\left.\mathrm{K}\right]$

$T_{\text {CHX-fluid }} \quad$ Temperature of the liquid water inside the $\mathrm{CHX}$ at the moment of condensation [ ${ }^{\circ} \mathrm{C}$ or $\mathrm{K}$ ]

$T_{\text {boil-out }} \quad$ Temperature of the cooling flow driven by the electric pump exiting the boiler $\left[{ }^{\circ} \mathrm{C}\right.$ or $\mathrm{K}$ ]

$\Delta T_{\text {int }} \quad$ Difference between $T_{\text {HHX-fluid }}$ and $T_{\text {CHX-fluid }}\left[{ }^{\circ} \mathrm{C}\right.$ or K] 


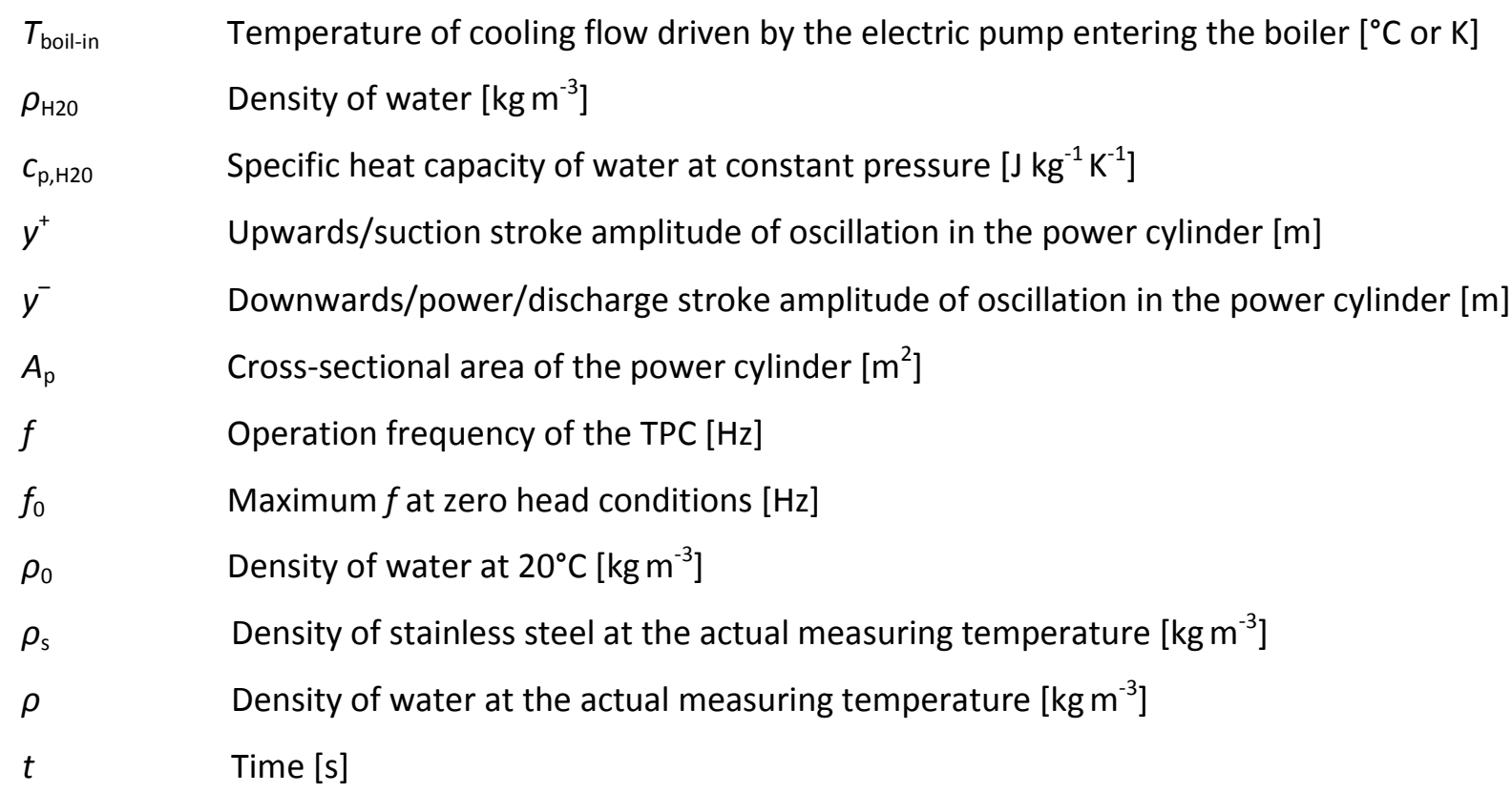

\section{Subscript}

0

S

$\max$

p

boil

$\mathrm{H}$,loss

$\mathrm{H}_{2} \mathrm{O}$

int

e

HHX-fluid

CHX-fluid

boil-in

boil-out

p

$\mathrm{CH}$
Zero head conditions; or $20^{\circ} \mathrm{C}$ conditions (for rotameter correction)

Stainless steel /solid (for rotameter float material)

Stalling, or near-stalling conditions

Power cylinder

Boiler

Heat losses from the boiler faceplate

Water

Internal to the TPC

Central heating circuit, or external

Fluid in the HHX

Fluid in the $\mathrm{CHX}$

Cooling flow driven by the electric pump entering the boiler primary $\mathrm{CH}$ heat exchanger Cooling flow driven by the electric pump exiting the boiler primary $\mathrm{CH}$ heat exchanger Pressure

Central heating, or central heating circuit 


\section{INTRODUCTION}

The depletion of finite fossil-fuel resources together with concerns, both health-related and environmental, relating to the release of product gases from fossil-fuel combustion $\left(\mathrm{CO}_{x}, \mathrm{NO}_{x}, \mathrm{SO}_{x}\right.$, particulates, etc.) to the atmosphere are acting as major drivers towards a higher efficiency and more sustainable energy future [1]. Essential components of such a future, depending on the energy demand in a particular setting, are the recovery and re-use of waste and low-grade heat, or the conversion of this heat to useful power. Low-grade (i.e. low temperature) waste heat is abundantly available in the industrial sector, and also in the domestic environment, while non-concentrated solar thermal and low-temperature geothermal energy are additional untapped energy sources with great potential if they can be harnessed simply, reliably and at low cost.

The desire to utilise renewable energy resources where possible has led to an enhanced interest in thermoacoustic heat engines. Importantly, these systems are capable of operating directly with thermal energy inputs, such as solar or waste heat, and further have no, or few, moving components in addition to typically employing an inert gaseous working fluid with little or no adverse environmental impacts. The first thermoacoustic devices that demonstrated the possibility of heat conversion to sound (acoustic power) were the Sondhauss and Rijke tubes [2]. The detailed study of the thermoacoustic oscillations in these devices has formed a basis on which thermoacoustic heat engines have been developed, by amongst other, Wheatley et al. [3,4], Backhaus and Swift [5], Ceperley [6], Sun et al. [7], Qiu et al. [8], Redlich and Berchowitz [9], Dai et al. [10], Luo et al. [11] and Tang et al. [12]. Engines based on travelling waves (in which pressure and specific volume are $90^{\circ}$ out of phase) with reversible heat transfer has been shown to outperform standing wave based systems (in which pressure and specific volume are in phase) that require intrinsically irreversible heat transfer to operate [5].

Fluidyne engines are a type of travelling wave thermoacoustic engine that employs liquid pistons thereby eliminating the need for mechanical moving parts and seals. A significant effort has gone into their developed for fluid pumping applications $[13,14]$. The efficiency of a Fluidyne engine decreases at high loads, i.e. while pumping against large pressure differentials, due to high frictional losses in the tuning line, which is required for the satisfactory operation of the engine due to its inherent reliance on inertia (i.e. fluid mass). By partially evaporating the liquid displacer piston $[15,16]$, higher power densities and larger displacement amplitudes at very low temperature differences were achieved, while paying a penalty in the form of poor thermal efficiencies.

This low thermal efficiency at high loads was attributed to the excessive power required to drive the fluid oscillations in the tuning line, which motivated efforts to devise alternate systems that eliminate the dependence on inertia [17]. This view has led to the introduction of a technology referred to as the 'Non-Inertive-Feedback Thermofluidic Engine' (NIFTE). This promising technology was recently proposed in Smith [17], who built an early small-scale prototype that employed an electrical heater as a heat source and devised a simple dynamic model for the purposes of early-stage engineering design. The NIFTE that has been shown to be well suited to the conversion of low-grade heat to hydraulic (fluid pumping) work, and has been demonstrated to operate across temperature differences between the heat source and the ambient of as low as $30^{\circ} \mathrm{C}[18]$. 
The NIFTE is as a two-phase thermofluidic oscillator, an oscillatory heat engine in which persistent thermodynamic oscillations (e.g. of pressure, volume and temperature) are generated and sustained within a connected space of chambers and tubes by steady external temperature differences. The oscillations are driven by and give rise to heat and fluid flows, which involve the periodic evaporation and condensation of the working fluid, which is contained within the device simultaneously in both phases.

With its few moving parts compared to mechanical heat engines as well as its lack of reliance on lubricants and dynamic seals, in common with most gas-phase thermoacoustic heat engines, the NIFTE promises improved reliability, extended lifetimes and low maintenance costs, while at the same time high manufacturing tolerances and a lack mechanism may (potentially) allow reduced capital costs. On account of these characteristics the NIFTE has attracted attention, specifically with regards to the performance capabilities of this technology.

The NIFTE has been the subject of a number of follow-on studies [18-20] whose aim has been to try to gain a better understanding of the coupling between the underlying thermal, fluid flow and thermodynamic processes and how this gives rise to the dynamic behaviour (i.e. oscillatory operation) of the device. In these studies, a number of first-order models for the NIFTE were proposed with emphasis on the improved description of key components and processes in the device. However, there has been a lack of experimental data against which these models can be validated. In this paper we provide experimental results of the NIFTE as a replacement for a central heating hot water circulator in a domestic setting. It is significant to point out that the present paper constitutes the first report on the employment of an early prototype of this technology in a practical application. 


\section{EXPERIMENTAL METHODS}

\subsection{Apparatus}

A schematic representation of the experimental setup employed in the present study is shown in Figure 1 . The apparatus was designed so as to allow the flexible variation of the input variables (i.e. the fuel burn rate in a domestic boiler burner, the flow-rates of fluid through the flow circuits), as well as access for temperature, pressure and flow-rate measurements at key positions in the system. Two separate fluid circuits were involved in the arrangement: (i) the central heating $(\mathrm{CH})$ circuit, described in Section 2.1.1 below; and (ii) the NIFTE [17-20] thermally powered circulator (TPC), described in Section 2.1.2. Water was chosen as the preferred liquid for both flow circuits. In the present experimental investigation the two circuits were kept separate in order to allow independent variations and a more detailed understanding of the overall system. It is intended that in a later stage the two circuits will be combined, thus creating a single central heating loop driven by the TPC.

\subsubsection{Central heating $(\mathrm{CH})$ system and boiler}

The TPC was attached to a modern, commercially available central heating system (Vaillant ecoTEC 824), modified for the purposes of the current investigation. The ecoTEC 824 is a wall-hung domestic 'high-efficiency' ( $90 \%)$ condensing combination boiler. Condensing boilers recover waste heat from the flue gases for increased efficiency, while combination boilers are capable of both central heating and direct hot water supply.

A pre-programmed fan unit within the boiler mixed natural gas with laboratory air. The resulting fuel-air mixture was sent to the combustion chamber where it was burnt in a spark-ignited premixed flame. Figure 1 shows that the flame was stabilised on a perforated cylindrical surface (0). The heat from the flame $Q_{\text {boil }}$ was used to heat the water $(1)$ in the central heating $(\mathrm{CH})$ circuit directly, as well as to provide heat to the evaporator or 'hot heat exchanger' (HHX; 9) of the TPC (this is described in detail below, in Section 2.1.2). The boiler heat setting was adjusted by an automatic control valve that regulated the flow-rate of the fuel-air mixture burnt in the combustion chamber, generating heat between 7 and $19 \mathrm{~kW}$.

The hot $\left(40-70^{\circ} \mathrm{C}\right) \mathrm{CH}$ water was pumped out of the boiler by an electric circulator pump (2) supplied with the boiler. Typically in a domestic central heating setting, the $\mathrm{CH}$ water is then circulated for space heating through a number of radiators placed throughout the household. In the present experimental arrangement the $\mathrm{CH}$ water was circulated instead through a large fan-assisted heat exchanger unit (3) that acted as the heat sink, rejecting the heat into the laboratory and cooling the $\mathrm{CH}$ water flow. The laboratory was ventilated continuously with a large ( $300 \mathrm{~W} ; 0.65 \mathrm{~m}^{3} / \mathrm{s}$ ) extractor fan, thus maintaining the laboratory temperature at $29 \pm 3{ }^{\circ} \mathrm{C}$. A rotameter (4) and an expansion vessel (5) were installed before the fan-assisted heat exchanger. The rotameter was used to measure the $\mathrm{CH}$ circuit flow-rate. The indicated flow-rate read from the scale was corrected for density variations due to temperature using the standard multiplier correction term $\left[\rho_{0}\left(\rho_{\mathrm{s}}-\rho\right) / \rho\left(\rho_{\mathrm{s}}-\rho_{0}\right)\right]^{1 / 2}$; where $\rho_{0}=998 \mathrm{~kg} / \mathrm{m}^{3}$ and $\rho$ are the water densities at the calibrated $\left(20^{\circ} \mathrm{C}\right)$ and the actual measuring conditions 
respectively, while $\rho_{\mathrm{s}}=8030 \mathrm{~kg} / \mathrm{m}^{3}$ is the density of the stainless steel float. The maximum applied correction was $1.2 \%$ at $70^{\circ} \mathrm{C}$. The expansion vessel was used as an accumulator, to steady the pressure and flow in the $\mathrm{CH}$ circuit. Specifically, it was used to absorb any pressurisation due to thermal expansion of the liquid water within the relatively short $\mathrm{CH}$ pipe work, but also in the case of steam formation in the boiler at low $\mathrm{CH}$ water flow-rates.

After the fan-assisted heat exchanger unit, the cold $\left(30-40^{\circ} \mathrm{C}\right)$ water was pumped back into the boiler by the electric pump, via the outside (shell-side) cooling flow channel $(6,7)$ of the condenser or 'cold heat exchanger' (CHX; 8). In Figure 1, (6) denotes the inlet and (7) the outlet of this stream. Thus, the flow-rate in the closed-loop $\mathrm{CH}$ circuit $U_{\mathrm{e}}$ was also affected by the pressure drop in the $\mathrm{CHX}$ of the TPC, and specifically in the shell-side cooling flow channel as shown in Figure 1. Two different $\mathrm{CHX}$ designs were used (described in Section 2.1.2), which resulted in $\mathrm{CH}$ water flow-rates of $U_{\mathrm{e}}=250$ and $320 \mathrm{~L} / \mathrm{hr}$ depending on the configuration (refer to Section 2.2 for further details). The electric pump was always run at full power.

In summary, the TPC being essentially a heat engine, rejected its heat initially to the $\mathrm{CH}$ water loop at the CHX, resulting in some preheating of the $\mathrm{CH}$ water before this entered the boiler, after which it was rejected to the laboratory by the fan-assisted heat exchanger unit, and finally to the atmosphere by the extractor fan. The level of pre-heating was measured at between 5 and $35 \%$ of the combustion chamber generated $Q_{\text {boil }}$ in the boiler.

\subsubsection{Thermally powered circulator (TPC)}

Referring again to Figure 1, the thermally powered circulator (TPC) comprised three main components: (i) the hot heat exchanger (HHX; 9); (ii) the cold heat exchanger (CHX; 8); and, (iii) the power cylinder (10). The HHX (9) consisted of tubes introduced into the boiler combustion chamber. At their lower end (11) the HHX tubes were connected to the inside channel (tube-side) of the $\mathrm{CHX}$ and at the top (12) they were connected to the top of the power cylinder. We will refer to these as the 'HHX-CHX connection' and 'vapour connection', respectively.

All HHXs and CHXs were custom made. Two different HHX designs were used to match two different designs for the CHX: (i) a large-capacity heavily finned HHX with large diameter channels ('TPC Configuration A'); and, (ii) a less intrusive HHX design with a reduced fin area and smaller diameter channels ('TPC Configuration B'). The corresponding designs for the matching CHXs were: (i) a long single shell-single tube concentric tubular CHX; and, (ii) a short single shell-multiple tube shell-and-tube $\mathrm{CHX}$. The long tubular $\mathrm{CHX}$ comprised a single large diameter tube, whereas the short shell-and-tube $\mathrm{CHX}$ comprised a number of small diameter tubes in parallel. We will refer to the former as the 'large-capacity' $\mathrm{HHX}-\mathrm{CHX}$ combination or TPC configuration, and to the latter as the 'smallcapacity' HHX-CHX combination or TPC configuration.

The power cylinder (10) was a circular tube constructed from a clear high-temperature plastic, which permitted the visual observation of the internal vertical oscillations of the liquid. The choice of material also provided superior insulating behaviour compared to glass [21,22]. The cylinder was connected at the top to the HHX tubes via the 'vapour connection', while at the bottom it was connected to a liquid 'power transmission line' (PTL; 13) as well as to the tube-side channel(s) of the CHX. We will refer to this pump-side connection between 
the power cylinder and the CHX as the 'feedback line' (14). The feedback line between the CHX and the power cylinder was kept as short as possible, as allowed by the configuration and was not varied.

The PTL connected the bottom of the power cylinder to the flow circuit (15) of the TPC. Two PTL hoses were used with different lengths $L_{\mathrm{PTL}}=2$ and $5 \mathrm{~m}$ (see Figure 1), but which were otherwise identical. Experiments with the two lengths were done in both the large- and small-capacity configurations of the TPC. The TPC flow circuit included: a Y-fitting with two check (or one-way) valves $(16,17)$, one on each branch but in opposite orientations; two vertical cylindrical reservoirs $(18,19)$, doubling as pressure accumulators (or expansion vessels); and, a combination of two valves placed in series (20), one ball valve and one gate valve.

The flow generated by the TPC in the PTL was purely oscillating (zero-mean) [17-20]. This was transformed to a unidirectional flow with the use of the Y-fitting and check valves. When the oscillating TPC generated an outward displacement stroke $\left(y^{-}>0\right.$ in Figure 1$)$ and hence a discharge of liquid from the power cylinder into the power transmission line, the check valve on one arm of the Y-fitting (16) opened, sending liquid into the discharge or high-pressure (HP) reservoir (18). During this discharge process the other (reversed) check valve in the second arm of the Y-fitting (17) ensured that liquid was not able to flow from the supply or low-pressure (LP) reservoir (19) through the Y-fitting back into the power transmission line. When the TPC generated an inward displacement stroke $\left(y^{+}>0\right.$ in Figure 1) and hence suction of liquid from the power transmission line back into the power cylinder, the check valve in first arm of the Y-fitting closed, and the check valve in the second arm of the Y-fitting opened allowing liquid to flow from the LP reservoir through the Y-fitting back into the power transmission line. The liquid that accumulated inside the HP reservoir was then forced through the ball and gate valves into the LP reservoir, and finally through the second arm of the Y-fitting to close the TPC flow circuit (15). Thus, the pressure (or head) rise across the TPC was equal to the difference between the pressures in the HP and LP reservoirs. For the purposes of the present investigation, the ball and gate valves were used to adjust externally the pressure drop in the TPC flow circuit, and thus also the pressure difference across the TPC.

Referring to Figure 2, each reservoir was a vertically oriented cylindrical volume filled partially with liquid and partially with air. The two connecting valves were adjusted to provide coarse and fine control of the mean pressure difference between the two reservoirs in the circuit, which was also the pressure rise across the TPC $\triangle P$, and consequently also of the flow-rate from the HP to the LP reservoir, i.e. the flow-rate in TPC flow circuit $U$. The LP reservoir was kept open to atmosphere, such that the pressure within it fluctuated slightly about atmospheric pressure. The pressure in the HP reservoir fluctuated about an elevated mean pressure determined by the valves, and was adjusted further by the addition or removal of compressed laboratory air from the top. The fluctuations in both pressures arose as a consequence of the pulsating displacement action of the TPC. The magnitude of these fluctuations was minimised effectively by maximising the percentage volume of the reservoirs occupied by air, resulting in amplitudes of no more than a few $\mathrm{cm}$.

Finally, the primary requirement from the working fluid of the TPC was that the chosen fluid evaporated in the $\mathrm{HHX}$ and condensed in the $\mathrm{CHX}$, subject to the temperatures within these components that could be achieved practically in our setup. A number of secondary requirements were also considered, such as cost and toxicity. The 
decision was made to select water as the working fluid for the TPC. Ultimately, the current study investigates the possibility of replacing the electric circulator in the $\mathrm{CH}$ circuit with the TPC, even though this has not been done here for measurement flexibility. An additional advantage of the decision to pick water as a common fluid in both the $\mathrm{CH}$ and TPC flow circuits is that any future attempt to connect the two circuits, thus removing the need for the electric circulator, will not require a device or scheme to maintain two different liquids separated.

\subsection{Measurement methodology}

Prior to operation, a note of the ambient temperature, pressure and humidity in the laboratory was made. A desired heat setting (fuel burn) $Q_{\text {boil }}$ was prescribed to the boiler control system, after which the $\mathrm{CH}$ boiler was switched on. Heat settings of $Q_{\text {boil }}=7,10,12$ and $15 \mathrm{~kW}$ were used in the experiments presented in this paper.

After switching on the boiler the fuel-air fan began to introduce the flammable mixture into the combustion chamber, while the electrical circulator began to circulate the water in the $\mathrm{CH}$ circuit. The water flow-rate in the $\mathrm{CH}$ circuit was $U_{\mathrm{e}}=250 \mathrm{~L} / \mathrm{hr}$ in all tests involving the large capacity TPC configuration (i.e. with the large-capacity $\mathrm{HHX}-\mathrm{CHX}$ combination), and $U_{\mathrm{e}}=320 \mathrm{~L} / \mathrm{hr}$ in all tests involving the small-capacity TPC configuration (i.e. with the small-capacity $\mathrm{HHX}-\mathrm{CHX}$ combination). A few seconds later continuous sparking was generated in the combustion chamber until the flammable fuel-air mixture was ignited and a stable flame successfully established. As the TPC started up and the flow-rate $U$ in the TPC flow circuit (and pressure in the HP reservoir) increased, the two coarse and fine flow control valves were adjusted to achieve a certain pressure difference $\triangle P$ across the TPC. It should be noted that this arrangement imposed a dynamic load on the TPC, that is, a pressure drop that resulted by a loss in dynamic pressure (or, dynamic head) in the flow through the valves in the $\mathrm{CH}$ flow circuit. This arrangement is different to that of a static load that would have been imposed had the TPC been connected so as to pump a liquid over a certain vertical height from one reservoir to another.

Two types of measurements were made: (i) visual observations of certain quantities on dials, gauges or displays and recording after some time was allowed for the system ( $\mathrm{CH}$ and TPC flow circuits) to reach steady state; and, (ii) continuous measurements of important quantities with electronic instruments and sampling by a Data Acquisition (DAQ) system, from the moment sparks appeared in the boiler for fuel ignition. For the latter, a 16-bit National Instruments USB-6259 DAQ device was used to record the output from important thermocouples and all pressure sensors. Sampling was done at a frequency of $10 \mathrm{~Hz}$. The raw sensor outputs were sent to a National Instruments SC-2345 signal conditioning connector block for low pass noise filtering, after which they where data-logged by the DAQ device onto a dedicated PC for processing. The DAQ system was switched on as soon as sparks appeared in the boiler combustion chamber, after which data was recorded over a time of 5 min.

From this point, a set of variables was measured for each TPC configuration (i.e. choice of HHX, CHX and power transmission length $L_{\mathrm{PTL}}$ ), boiler heat setting $Q_{\mathrm{boil}}$, and control valve setting in the TPC flow circuit that effectively set the relationship between the flow-rate $U$ and pressure difference $\Delta P$. These included measurements at key positions: (i) within the TPC (the temperatures within the $\mathrm{HHX}, \mathrm{CHX}$, power cylinder, $\mathrm{HHX}-\mathrm{CHX}$ connection and 
vapour connection); (ii) in the TPC flow circuit (the temperature and pressure inside the LP and HP reservoirs, and the liquid displacement amplitude and frequency in the power cylinder); and (iii) in the CH circuit (the circuit flowrate $U_{e}$, the temperature of the inlet and outlet flow from the $\mathrm{CHX}$, and the temperature of the inlet and outlet flow from the boiler). These measurements are either reported directly, used to estimate dependent quantities that are presented in this paper, or used during the runs to confirm steady-state behaviour of the overall system.

\subsubsection{Pressure}

The pressure in the HP reservoir was measured with an electronic pressure sensor (PG-1 in Figure 2), the output from which was calibrated using a mercury manometer. The pressure in the LP reservoir was found to vary by no more than $\pm 0.1 \mathrm{~m}$ about atmospheric pressure. The final pressures were further corrected for small hydrostatic differences in the reservoirs by using a scale, as indicated in Figure 2 . The reported mean pressure difference between the HP and LP reservoirs, which was also the dynamic load pressure rise across the TPC $\triangle P$, was averaged over 10 pulsations. For a typical measurement of $\Delta P$ see Figure 3 in Section 3.1.1. In cases where the pump stalled, the maximum attainable $\Delta P$ is reported. The total uncertainty in the reporting of $\Delta P$ is $\pm 0.1 \mathrm{~m}$. Also, it was established that cycle-to-cycle variations in $\Delta P$ had a standard deviation of $0.3 \mathrm{~m}$.

\subsubsection{Temperature}

Two continuous temperature measurements were made using miniature $(0.25 \mathrm{~mm}$ and $0.50 \mathrm{~mm}$ diameter) mineral insulated K-type thermocouples. The two thermocouples were placed: (i) at the top of the power cylinder (indicated by label 'TC-1' in Figure 1); and, (ii) inside the $\mathrm{CHX}$ near the HHX-CHX connection ('TC-2' in Figure 1). These were used to report the mean temperature of the steam at the top of the power cylinder at the moment of

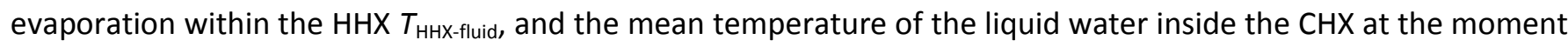

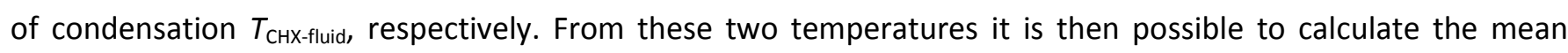
'internal' temperature difference as seen by the thermodynamic cycle undergone by the working fluid of the TPC, i.e. $\Delta T_{\text {int }}=T_{\text {HHX-fluid }}-T_{\text {CHX-fluid. }}$ The raw thermocouple signals were connected to an Audon TCK-4 amplifier, which also preformed on-board cold junction compensation. The output from the thermocouple amplifier was read by the DAQ system. Finally, the saved voltage data was converted to temperature based on information provided in the manufacturer's datasheet and standard thermocouple conversion equations ${ }^{1}$. It has been established that $T_{\text {HHX-fluid }}$ has a total uncertainly of $\pm 0.5 \mathrm{~K}$ and a cycle-to-cycle standard deviation of $1.5 \mathrm{~K}$, whereas $T_{\text {CHX-fluid }}$ has a total uncertainly of $\pm 1.0 \mathrm{~K}$ and a cycle-to-cycle standard deviation of $2.5 \mathrm{~K}$. The total uncertainty includes calibration and non-linearity in amplification errors.

Two further temperature measurements were made, indicated by labels ' $T-1$ ' and 'T-2' in Figure 1. These were of the temperature of the $\mathrm{CH}$ flow entering $T_{\text {boil-in }}$ and exiting $T_{\text {boil-out }}$ the boiler at steady state. Both temperatures were read from an Omega HH-21 thermocouple display unit (stated accuracy from the manufacturer $\pm 1 \mathrm{~K}$ ), such

\footnotetext{
${ }^{1}$ Following http://srdata.nist.gov/its90/main
} 
that the total error associated with these measurements is $\pm 2 \mathrm{~K}$. From these temperatures and the knowledge of the flow-rate $U_{\mathrm{e}}$ in the $\mathrm{CH}$ flow circuit it was possible to calculate the heat transferred from the flame into the $\mathrm{CH}$ circuit, $Q_{\mathrm{CH}}=\rho_{\mathrm{H} 20} U_{\mathrm{e}} C_{\mathrm{P}, \mathrm{H} 20}\left(T_{\text {boil-out }}-T_{\text {boil-in }}\right)$. Further, given our knowledge of the total flame heat $Q_{\text {boil, }}$ it was possible to estimate the heat from the flame that went into the TPC at the HHX, $Q_{H H X}=Q_{\mathrm{boil}}-Q_{\mathrm{CH}}-Q_{H, \text { loss, }}$ where $Q_{H, \text { loss }}$ is an estimation of the heat losses from the boiler faceplate based on actual measurements of the faceplate temperature and area. The heat loss $Q_{H, \text { loss }}$ was between 1.0 and $1.7 \mathrm{~kW}$, which was 10 to $15 \% Q_{\text {boil, }}$ such that the ratio $Q_{H, \text { loss }} / Q_{H H X}$ was between 20 to $50 \%$. It was higher at higher boiler settings $Q_{\text {boil }}$ due to higher faceplate temperatures. From Table $1 Q_{\mathrm{HH}}$ was found to be between 2.1 and $5.5 \mathrm{~kW}$.

\section{$\underline{2.2 .3 \text { Flow-rate }}$}

The vertical oscillatory motion of the liquid level (liquid-vapour interface) in the transparent power cylinder was observed by eye. Upwards positive (suction) $y^{+}$and downwards negative (discharge) $y^{-}$oscillation amplitudes were defined relative to an 'equilibrium' level that coincided with the mid-height of the HHX-CHX connection, as illustrated in Figure 1. The two amplitudes were read with the help of a ruler fixed directly onto the power cylinder in order to minimise errors. Multiple realisations were recorded for both $y^{+}$and $y^{-}$. In this paper we report amplitudes averaged over 10 realisations, which were taken during a time when observations indicated that the TPC had settled to a steady state.

For the frequency of oscillations we inspected the recorded pressure plots generated from the pressure gauge in the HP reservoir (PG-1 in Figure 2). We report an averaged frequency $f$ calculated from the average period of oscillations over 10 steady-state cycles. The total uncertainly in the reporting of $f$ is $\pm 0.01 \mathrm{~Hz}$. The cycle-to-cycle standard deviation was $0.03 \mathrm{~Hz}$. Hence, the TPC flow-rate was evaluated from $U=\left(y^{+}-y^{-}\right) A_{p} f$, where $A_{p}$ is the cross-section of the power cylinder.

Repeated runs were conducted in order to confirm that the performance of the TPC and the associated results were repeatable, but also to give an estimate of any variability. This process, together with an error analysis based on each variable, revealed that the total uncertainly in $U$ is $\pm 15 \mathrm{~L} / \mathrm{hr}$ in the case of the small-capacity TPC and $\pm 20 \mathrm{~L} / \mathrm{hr}$ for the large capacity configuration, respectively. However, as with other variables, cycle-to-cycle variations were more significant with a standard deviation of $50 \mathrm{~L} / \mathrm{hr}$. 


\section{OPERATIONAL OBSERVATIONS}

\subsection{Normal operation}

The TPC is an oscillatory heat engine, whose operation relies on the continuous sequential alternation between two stages: (i) the power (or discharge) stroke; and (ii) the suction stroke. In these stages positive displacement of fluid (in our case, water) is caused by the generation (by evaporation during the power stroke) and reduction (by condensation during the suction stroke) of a volume of water as this undergoes a two-phase thermodynamic cycle. For a detailed description of the TPC cycle refer to Ref. [17].

Initially, with the boiler off, the entire internal volume of the TPC (including the HHX, CHX tubes, power cylinder and all connections) contains water in the liquid phase at ambient temperature. Soon after the establishment of the flame in the boiler combustion chamber the heat originating from the hot combustion gases causes the water in the HHX to evaporate. After some initial transients the TPC reaches steady-state oscillations.

During the power stroke the HHX utilises a part $\left(Q_{H H X}\right)$ of the total heat $\left(Q_{\text {boil }}\right)$ generated in the boiler combustion chamber to evaporate water contained in the HHX. This occurs during the time when the water level (water-steam interface) moves vertically upwards from the $\mathrm{CHX}$ into the HHX. The generated steam flows upwards within the HHX tubes, through the vapour connection and into the top of the power cylinder. This causes the pressure in the power cylinder to increase and displaces the water in the power cylinder downwards and out into the HP reservoir. The effectiveness of the evaporation process determines the negative displacement power amplitude $y^{-}$in the TPC. The heat removal from the hot HHX due to the contact with cold water is associated with a quenching of the solid walls of the HHX tubes, leading to lower wall temperatures and progressively reduced steam generation ability in the HHX. Further, the steam introduced into the top region of the power cylinder comes into contact with the colder walls in this space, which leads to partial condensation there. This loss mechanism, known as entrance condensation, was also identified in the early NIFTE prototype in Ref. [17].

The power stroke process described in the above paragraph results in a flow into and pressurisation of the HP reservoir. A clearly defined steam-water interface can be observed moving downwards along the height of the power cylinder. The downward displacement of the water level in the power cylinder eventually results in a situation in which the water level drops below the water-steam interface in the HHX that is evaporating. This causes a hydrostatic pressure difference across the feedback line that connects the HHX with the power cylinder, which in turn eventually causes the water level in the HHX to drop into the $\mathrm{CHX}$.

The next stage is the suction stroke, which relies on the capacity of the $\mathrm{CHX}$ to remove heat from the steam contained within the $\mathrm{CHX}$ tubes. When the water-steam interface moves from the HHX into the $\mathrm{CHX}$ the steam condenses into water by contact with the cold walls. This leads to a reduced pressure (suction) that pulls the water in the power cylinder upwards and results in flow into the power cylinder from the LP reservoir. The steamwater interface can then be observed moving upwards along the height of the power cylinder. The effectiveness of the condensation stage determines the positive displacement suction amplitude $y^{+}$of the TPC. When the water level in the power cylinder rises above the water-steam interface in the $\mathrm{CHX}$ that is involved in condensation 
there is a hydrostatic pressure difference across the feedback line that connects the $\mathrm{CHX}$ with the power cylinder. This pressure difference increases until it eventually causes the water level in the CHX to rise into the HHX, where the evaporation process associated with the power stroke will repeat itself.

The heat rejected to the walls of the $\mathrm{CHX}$ during condensation in the suction phase flows into the $\mathrm{CHX}$ cooling water stream, and finally into the fan-assisted heat exchanger unit where it is rejected to the laboratory. The heat deposited at the $\mathrm{CHX}$ increases the temperature of the $\mathrm{CHX}$ walls and progressively reduces its capacity for condensation. The durations of the power and suction strokes determine the oscillation period of the pump.

Figure 3(a) shows a typical time plot of the pressure difference across the TPC $\triangle P$ during normal operating conditions. This particular low-load operating condition involves a near-zero time-averaged pressure difference - The oscillations are periodic, smooth and described relatively well by a single sinusoid, although the pointed peaks and troughs suggest that it does exhibit some (limited) higher frequency content. This is an important point as it implies that, at least in these conditions, the TPC behaviour is dominated by processes whose frequency spectrum is discrete and characterised strongly by a single frequency component with some lower harmonics.

Normal operation was associated with a root mean square $(\mathrm{rms})$ in the oscillations of $\Delta P$ in the range $0.1-0.3$ $\mathrm{m}$ (e.g. see Figure $3(\mathrm{a})$ ) for operation below $-=1 \mathrm{~m}$, and in the range $0.1-0.5 \mathrm{~m}$ for operation up to $-=5$ $\mathrm{m}$, increasing with increasing - This corresponded to a relative oscillation in the rms of $\Delta P$ with respect to the mean - of up to $30 \%$ for $-<1 \mathrm{~m}$, to less than $20 \%$ for - between 1 and $6 \mathrm{~m}$, to less than $10 \%$ for $->6$ $\mathrm{m}$, decreasing with increasing - .

The time plot in Figure 3(b) was generated at high load and shows the behaviour of the TPC in stalling conditions. Note the three stalling and re-starting processes that have been captured during this recording. The stall points (at $t \sim 25,120$ and $265 \mathrm{~s}$ ) are associated with high pressure and almost zero flow-rate. The high pressure is caused by the dynamic loss through the valves in the TPC flow circuit that have been set to be almost closed. In these stalling conditions, the much reduced flow-rate leads gradually to a reduction in the dynamic pressure loss, which allows the TPC to resume its pumping action, driving an increasing flow into the TPC flow circuit, increasing the pressure drop across the valves, and so on.

Figure 4 shows time plots equivalent to Figure 3(a), i.e. taken during normal steady-state operation, of the temperature of the solid walls of the HHX $\left(T_{\text {HHX-wall; }}\right.$ in Figure $\left.4(a)\right)$ and of the $\mathrm{CHX}\left(T_{\text {CHX-wall; }}\right.$ in Figure 4(b)). Both plots belong to the same experimental run. The thermocouples from which the measurements of $T_{\mathrm{HHX} \text {-wall }}$ and $T_{\mathrm{CHX}-}$ wall were obtained were positioned approximately $2 / 3$ of the way into the $\mathrm{HHX}$ and $\mathrm{CHX}$, respectively. Similarly, Figure 5 shows time plots of the working fluid temperature at the top of the $\mathrm{HHX}\left(T_{H H X-f l u i d}\right.$; Figure $\left.5(a)\right)$ and in the

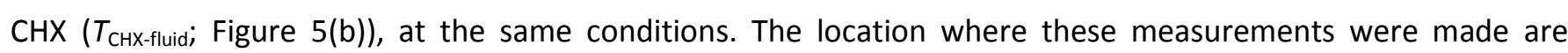
indicated in Figure 1, which shows thermocouples TC-1 (used for $T_{\text {HHX-fluid }}$ ) and TC-2 (used for $T_{\text {CHX-fluid). }}$ ).

Figure $4(\mathrm{a})$ reveals that the temperature of the HHX tubes $T_{\text {HHX-wall }}$ fluctuates between approximately $100{ }^{\circ} \mathrm{C}$ at the point in the cycle when $\mathrm{HHX}$ is flooded by liquid water (when $y^{+}$is close to its peak value) and $550-600{ }^{\circ} \mathrm{C}$ when the HHX is empty of water (such that $y^{-}$is close to its peak value). Five stages are observed in the $\mathrm{HHX}$ 
temperature cycle. Starting from Point ' $\mathrm{A}$ ' at $t \sim 2 \mathrm{~s}$ in Figure 4(a): (i) a steep temperature rise from $T_{\mathrm{HHX} \text {-wall }} \sim$ $100^{\circ} \mathrm{C}$ to $T_{\mathrm{HHX} \text {-wall }} \sim 400^{\circ} \mathrm{C}$; (ii) a continuing temperature increase but with a smaller rate of change from $T_{\mathrm{HHX} \text {-wall }} \sim$ $400^{\circ} \mathrm{C}$ to the peak temperature $T_{\text {HHX-wall }} \sim 550-600{ }^{\circ} \mathrm{C}$; (iii) a gradual temperature decrease from the peak temperature to $T_{\mathrm{HHX} \text {-wall }} \sim 400^{\circ} \mathrm{C}$; (iv) a steep temperature drop down to $T_{\mathrm{HHX} \text {-wall }} \sim 100{ }^{\circ} \mathrm{C}$; and (v) a short time spent at a constant temperature at the lowest end $\left(T_{\text {HHX-wall }} \sim 100^{\circ} \mathrm{C}\right.$ ). The steep gradients in Stages (i) and (iv) are associated with the liquid-vapour interface passing over the position of the thermocouple where the measurement is made. In Stage (i) the liquid water level passes this position in a downwards direction $\left(\mathrm{d} y^{+} / \mathrm{d} t<0\right.$ ) as the water level falls from the HHX into the CHX. During this time, first the HHX and then the CHX are gradually emptied of water, which flows through the feedback line into the lower end of the power cylinder. The temperature of the $\mathrm{HHX} T_{\mathrm{HHX} \text {-wall }}$ rises suddenly from $100{ }^{\circ} \mathrm{C}$ to $400-450{ }^{\circ} \mathrm{C}$, as the solid surfaces become uncovered. Conversely, in Stage (iv) the water level passes the thermocouple position in an upwards direction $\left(\mathrm{d} y^{+} / \mathrm{d} t>0\right)$, as the $\mathrm{HHX}$ is filled. The temperature of the $\mathrm{HHX} T_{\mathrm{HHX} \text {-wall }}$ drops abruptly from $400-450{ }^{\circ} \mathrm{C}$ to $100{ }^{\circ} \mathrm{C}$ as the solid surfaces are covered by the water, and remains at this low temperature for as long as the water level is above the thermocouple location (this is Stage (v)). Stages (ii) and (iii) are recorded during the time when the water level is in the $\mathrm{CHX}$ and $\mathrm{HHX}$ respectively, and in both cases moving upwards $\left(\mathrm{d} y^{+} / \mathrm{d} t>0\right)$. Stage (iii) is related to the flow of steam through the $\mathrm{HHX}$ in an upwards direction. The steam is generated below the thermocouple position following the introduction of water from the $\mathrm{CHX}$ into the $\mathrm{HHX}$, and then flows through $\mathrm{HHX}$ and the vapour connection into the top part of the power cylinder.

The thermal stressing in the CHX walls is considerably smaller than that in the HHX. Figure 4(b) shows a typical time trace of the $\mathrm{CHX}$ wall temperature, which indicates that this is of the order of $30{ }^{\circ} \mathrm{C}$, going from a low of $65{ }^{\circ} \mathrm{C}$ to a high of high of $95{ }^{\circ} \mathrm{C}$ in half the cycle period. It can be seen that, in the recorded conditions, no evaporation is possible in the $\mathrm{CHX}$ whose walls are retained at $T_{\mathrm{CHX} \text {-wall }}<100^{\circ} \mathrm{C}$ by the flow of the cooling water on the tube side (see Figure 1 and Section 2.1.1).

The working fluid temperatures shown in Figure 5 indicate that a small degree of superheating and subcooling takes place during the cycle. The saturation temperature of water/steam is not expected to change by more than a few degrees (typically $2-3^{\circ} \mathrm{C}$ ) due to the observed pressure fluctuations $(\sim 0.5-1 \mathrm{~m})$. This is smaller than the observed $5-10{ }^{\circ} \mathrm{C}$ fluctuation in $T_{\text {HHX-fluid }}\left(\sim 8{ }^{\circ} \mathrm{C}\right.$ in Figure $\left.5(\mathrm{a})\right)$, which nonetheless is considered small. This is a useful finding as it confirms the conventional assumption that is made in the modelling of these systems [17-20], that the thermodynamic cycle occurs mainly within the saturation region without superheating or subcooling.

\subsection{Irregular operation}

Variability in the oscillatory behaviour of the TPC under consideration was observed during some experimental runs in the form of beating. The beating phenomenon was readily recognised both by visual observation and by an irregularity in the resulting pressure plots. An example of this is behaviour shown in Figure 4. 
The observations of beating confirm earlier ones made in a simpler NIFTE prototype in Ref. [17], where the author linked the phenomenon to the large thermal capacitance of the heat exchanger blocks. Beating arises generally due to a slight mismatch between two underlying simultaneous oscillatory signatures within the same signal (in our case, flow-rate or pressure). A possible reason for this observed behaviour in the present device could be the mismatching between the heat exchange and phase change processes taking part in the HHX and $\mathrm{CHX}$, and the flow processes taking part in the power cylinder and TPC flow circuit.

Finally, in some experimental runs, especially with the short PTL, low amplitude oscillations were observed even when the valves connecting the pressure reservoirs were fully open, whence large amplitudes were expected. In some cases, the pump stopped pumping. It was not entirely clear what was causing this behaviour; however, a possible reason for this could be a mismatch between the HHX and CHX heat exchange capacities.

It was noted in Ref. [17] that two loss mechanisms occur in this device due to the properties of the solid materials from which it is constructed, and that these mechanisms can lead to engine stall. The first mechanism, known as 'entrance condensation', is caused by the pressure variations within the engine and involves the periodic condensation and evaporation of the working fluid on the interior surfaces, which is accompanied by a periodic flow of heat into and out of the solid walls. As explained in Ref. [17], this leads to a direct loss in pressure during the discharge stroke as vapour condenses on the colder walls in the top part of the engine, and a parasitic pressure rise during the suction stroke as the condensate re-evaporates. The second loss mechanism, referred to as the 'shuttle loss', occurs in the power cylinder over the height in which the liquid level moves upwards and downwards, and involves the periodic storage of heat in the solid walls of the power cylinder during the high pressure discharge stroke, and the periodic removal of heat from the walls by the liquid during the low pressure suction stroke. As explained in Ref. [17], the shuttle loss causes a direct pressure loss approximately in phase with the displacement of the liquid in the power cylinder. In addition, this loss mechanism was stated as being more pronounced than the entrance condensation loss. Both loss mechanisms worsen with increasing load (i.e. pressure), which leads to increased temperature amplitudes in the vapour containing regions of the engine.

It is evident that these loss mechanisms occur predominantly at high loads and cannot be responsible for the stall observed at low loads in the present investigation. The finding of an additional loss mechanism in this device, and by extension similar oscillator engines, is an important development. Nevertheless, if the underlying reason for this behaviour is indeed linked to the design of the HHX and CHX as suggested above, we expect the solution to this problem to be relatively straightforward. 


\section{RESULTS AND DISCUSSION}

\subsection{Pumping performance ( $U$ vs. $\Delta P)$}

Regular operation reveals trends in which the mean rectified (unidirectional) flow-rate in the TPC flow circuit $U$ decreases monotonically as the head $\triangle P$ that is applied across the TPC (i.e. between the HP and LP reservoir, with the use of the valves) is increased. This is also typical of common electrical circulators. As a consequence, the highest flow-rate $U_{0}$ (presented in Section 4.1.1) is achieved by the TPC when the head difference across the device is almost zero, and the maximum head achievable by the device $\Delta P_{\max }$ (presented in Section 4.1.2) is attained at stalling conditions when the flow-rate drops to 'almost' ${ }^{2}$ zero. The $U$ against $\Delta P$ performance characteristic of the TPC in the four different investigated configurations is summarised in Figure 7.

Figure 7(a) shows results generated by the TPC with the small-capacity HHX-CHX combination and the short $\operatorname{PTL}\left(L_{\mathrm{PTL}}=2 \mathrm{~m}\right)$. A similar pumping capability is observed at low $\Delta P$ between the two employed heat settings $Q_{\text {boil }}$ $=10$ and $15 \mathrm{~kW}$. On the other hand, the stalling behaviour of the TPC (i.e. the operating point at near-zero flowrate $U$ and maximum head difference $\Delta P_{\max }$ ) deteriorates at the higher heat setting (i.e. $\Delta P_{\max }$ reduces significantly). Figure 7(b) concerns the same small-capacity TPC configuration as that in Figure 7(a), but with the PTL replaced by a longer length of hose $\left(L_{\mathrm{PTL}}=5 \mathrm{~m}\right)$. At low $\Delta P$ the flow-rate $U$ is again similar at both $Q_{\text {boil }}=10$ and $15 \mathrm{~kW}$ heat settings, but once again, there is a significant deterioration of the pumping capability at medium and high $\Delta P$, including a greatly reduced $\Delta P_{\max }$, as the boiler setting is increased from $Q_{\text {boil }}=10$ to $15 \mathrm{~kW}$.

Referring to Figures 7(c) and 7(d), the TPC configuration involving the large-capacity HHX-CHX combination shows a much more robust high head performance, to the variations in the boiler heat setting, compared to the small-capacity TPC. With a short PTL of $L_{\text {PTL }}=2 \mathrm{~m}$ (Figure 7(c)) there is an improved pumping performance at low $\Delta P$ due to the increase in $Q_{\text {boil, }}$ but a decrease in performance at higher $\Delta P$, including a small reduction in $\Delta P_{\max }$. Results obtained with the longer $L_{P T L}=5 \mathrm{~m}$ PTL (Figure $7(\mathrm{~d})$ ) reveal a much more significant, and also nonmonotonic, effect of $Q_{\text {boil }}$ on the pumping capacity at the lower to medium range of investigated $\Delta P$. Increasing $Q_{\text {boil }}$ from 10 to $12 \mathrm{~kW}$ results in a considerably reduced pumping performance for the same $\Delta P$, but increasing $Q_{\text {boil }}$ again from 12 to $15 \mathrm{~kW}$ leads to a slight improvement and recovery in $U$. On the other hand it is interesting to observe that, despite this earlier conclusion concerning the lower to medium $\triangle P$ s, the maximum pumping flowrate $U_{0}$ is not noticeably affected by $Q_{\text {boil }}$ at the minimum (zero) head conditions. At the opposite end of the plots, i.e., high to stalling $\Delta P \mathrm{~s}$, the pumping flow-rates at the low and medium ( $Q_{\text {boil }}=10$ and $12 \mathrm{~kW}$ ) heat settings are similar, but shows a small reduction at higher $Q_{\text {boil }}=15 \mathrm{~kW}$, as was the case with the shorter PTL and also with the small-capacity TPC configurations discussed in the previous paragraph.

From an overall inspection of Figure 7(a) to Figure $7(d)$ it is possible to conclude that the larger capacity (and size) heat exchangers of TPC Configuration B allow an improved performance (in particular, a higher flow-rate at a given $\Delta P$ ) with respect the smaller Configuration $A$. This would have been expected, since a larger heat exchanger

\footnotetext{
${ }^{2}$ Recall that $\triangle P$ is a dynamic (pressure) load across the TPC, which would also have fallen to zero had the flow through the $\mathrm{CH}$ and TPC flow circuits completely stalled.
} 
area should normally lead to a greater heat exchanger, a greater volume of working fluid (water) involved in phase change, and thus, a greater ability to generate a positive displacement of the liquid piston into and out of the load. In addition, on comparing Figure $7(a)$ to Figure $7(b)$ and Figure $7(c)$ to Figure $7(d)$, it is apparent that lengthening the PTL leads generally to an improved pumping capability for the TPC, irrespective of the selected $\mathrm{HHX}-\mathrm{CHX}$ combination. The only exception to this (discussed in the next section) is found at zero loads with the small capacity HHX-CHX combination. Certainly, a longer PTL is associated with an effective load, as seen by the TPC, that has both a higher flow resistance and a higher flow inertia. Given that the plots in Figure 7 suggest that a higher flow resistance (and thus, higher dynamic head $\triangle P$ across the TPC) leads to lower flow-rate $U$, it may be concluded that the beneficial outcome of the longer PTL arises from the increased flow inertia in the load line, in agreement with the model predictions in Refs. $[19,20]$.

\subsubsection{Maximum (zero head) flow-rate}

In Table 2 we compile the results for the maximum flow-rate $U_{0}$ measured in zero head conditions for the various TPC configurations, extracted from Figure 7. The results for $U_{0}$ are also shown in Figure 8 , as a function of the heat that is taken into the TPC at the HHX, $Q_{H H X}$ (see Figure 1 for a definition of $Q_{H H X}$, and also Table 1 for the relation of $Q_{H H x}$ to $Q_{\text {boil }}$ ). This heat would go towards evaporating the liquid water within the TPC, which is expected to be the key process in determining the device's pumping capability $U_{0}$ at zero load. Figure 8 shows multiple results from a number of independent repeat runs (e.g., three separate runs with TPC Configuration B and $L_{\mathrm{PTL}}=5 \mathrm{~m}$ at $Q_{\mathrm{HHX}} \sim 3.6 \mathrm{~kW}$ ), whereas Table 2 only contains an average value for $U_{0}$ at each investigated $Q_{\text {boil. }}$

As mentioned above, the best performance is associated with TPC Configuration B, i.e. the large-capacity TPC, and when employing the long PTL. It can be observed that in this configuration, $U_{0}$ is not affected by $Q_{\text {boil }}$ (or, $Q_{H H X}$ ). In fact, $U_{0}$ is not affected significantly by $Q_{\text {boil }}$ or $Q_{H H X}$ in any of the TPC configurations, except in the case of the large-capacity HHX-CHX (Configuration B) with the short PTL, where it increases initially from $550 \mathrm{~L} / \mathrm{hr}$ at $Q_{\text {boil }}$ $=7 \mathrm{~kW}\left(Q_{\mathrm{HHX}} \sim 2.6 \mathrm{~kW}\right)$ to $720 \mathrm{~L} / \mathrm{hr}$ at $10 \mathrm{~kW}\left(Q_{\mathrm{HHX}} \sim 3.0 \mathrm{~kW}\right)$. It is noted however that, even in this case, a further increase in $Q_{\text {boil }}$ to $12 \mathrm{~kW}\left(Q_{H H x} \sim 3.6 \mathrm{~kW}\right)$ produces no further strong increase in $U_{0}$, although a very slight upwards trend may be discerned in Figure 8. Even with large variations in $Q_{\mathrm{HHX}}$ (of a factor of $\sim 2$, going from about $2.5 \mathrm{~kW}$ to $5 \mathrm{~kW}$ ), the pumping capability of a particular configuration at zero head $U_{0}$ does not show a noticeable increase, as would have been expected. Intuitively, higher heat inputs to the same TPC would be expected to yield increased quantities of steam from evaporation, increased displacements of the water in the power cylinder and consequently increased flow rates. This interesting observation suggests that the HHXs in both TPC configurations possibly reach an optimum limit in their ability to transfer heat to (and thus to evaporate) the liquid water at $Q_{H H X}=2.5-3.0 \mathrm{~kW}$, after which only marginal increases in $U_{0}$ can come from further increases in $Q_{\mathrm{HHX}}$. The data in Figure 8 indicate that for the large-capacity $\mathrm{HHX}$ this limit is possibly at $Q_{\mathrm{HHX}} \sim 3.0 \mathrm{~kW}$. Moreover, it is expected that the small-capacity HHX would reach this limiting point at a lower heat flow-rate $Q_{H H x}$, which may explain why this behaviour is not observed in the results from this TPC configuration, whereby $U_{0}$ is independent of $Q_{\text {boil }}$ and $Q_{H H x}$ within the experimental uncertainty and repeatability. 
The maximum pumping capacity $U_{0}$ of the small-capacity TCP configuration (in the approximate range $600-$ $650 \mathrm{~L} / \mathrm{hr}$ over the range in $Q_{\mathrm{HHX}}=2.9-4.7 \mathrm{~kW}$ ) lies in between 70 and $90 \%$ of that of the large-capacity TPC configuration (in the approximate range $700-850 \mathrm{~L} / \mathrm{hr}$ over the range in $Q_{\mathrm{HHX}}=3.4-5.5 \mathrm{~kW}$ ). The average discrepancy between the two pumps over the entire range of conditions is $75 \%$, which is of the order of the difference in their available area for heat exchange, which adds to the suggestion that the pumping performance of the TPC is strongly set by the HHX: the larger HHX is able to transfer larger quantities of heat from the boiler flame to evaporate water in the TPC, which results in increased flow rates at zero head.

Furthermore, for a given TPC configuration the PTL also has an effect on the maximum pumping capacity $U_{0}$ over the investigated range of $Q_{\mathrm{HHX}}$. Lengthening the PTL from 2 to $5 \mathrm{~m}$ in the small-capacity TPC (Configuration A) results in a very marginal decrease in $U_{0}$ of about $6 \%$ or $30-50 \mathrm{~L} / \mathrm{hr}$ (from 650 to $600-620 \mathrm{~L} / \mathrm{hr}$ ), whereas in the large-capacity TPC (Configuration B) the same lengthening of the PTL results in a more substantial increase in $U_{0}$ of about $20 \%$ or $130-150 \mathrm{~L} / \mathrm{hr}$, from $700-720$ to $850 \mathrm{~L} / \mathrm{hr}$. The decrease in $U_{0}$ in Configuration $A$ can be explained to a large extent in terms of the $\sim 10 \%$ decrease in the operating frequency of the TPC $f_{0}$ associated with the longer PTL (this is reported in Table 4 and discussed in Section 4.2.1). On the contrary, the decrease in $U_{0}$ in Configuration B cannot be explained in terms of $f_{0}$, which in fact is unaffected by PTL (see Table 4), and can only be due to an increased capacity to evaporate the working fluid. It was stated above that a longer PTL is associated with a higher effective load flow inertia, which may be beneficial in the operation of the TPC $[19,20]$. It is not clear for what reason this is not the case in the small-capacity TPC, especially given the fact that from Table 1 the heat into the HHX, $Q_{H H X}$, at the same $Q_{\text {boil }}$ is approximately the same between the short and long PTLs.

The observations above suggest that the heat input to the TPC, which should affect the maximum flow rate at zero head $U_{0}$, is not determined by the heat setting $Q_{\text {boil, }}$ but by the design and choice of the HHX (and perhaps $\mathrm{CHX}$, or other components), at least over the range of investigated conditions. Note that, ideally, the heat input to the TPC would go towards evaporation and consequently displacement of fluid, especially at zero head. On comparing the two TPC configurations with each other this effect should be considered alongside the fact that the frequency of the large-capacity TPC is lower by an average $25 \%$ compared to that achieved in the small-capacity TPC (again from Table 4). Hence, the $25 \%$ higher flow observed with the large-capacity TPC are expected to arise as a consequence of increased volumetric steam generation ability of the order of $\sim 60-70 \%$.

\subsubsection{Maximum (stalling) head}

Table 3 and Figure 9 summarise the maximum head capability of the TPC, $\Delta P_{\max }$, measured in stalling (negligible flow) conditions for the various configurations, again extracted from Figure 7. From Table 3 and Figure 9 (a) it can be seen that, as with for maximum flow-rate $U_{0}$, the best performance is associated with the largecapacity TPC and when employing the longer PTL. The improvement in $\Delta P_{\max }$ when changing from the small capacity to the large-capacity TPC is between $25-55 \%$, while the equivalent improvement when changing from the short to the long PTL is about $35-50 \%$ in Configuration A and $30-40 \%$ in Configuration B. Specifically, these 
relative improvements when changing the PTL correspond to noteworthy (and similar) increases in $\Delta P_{\max }$ by $1.5-$ $2.5 \mathrm{mH}_{2} \mathrm{O}$ in both configurations, when increasing $L_{\mathrm{PTL}}$ from 2 to $5 \mathrm{~m}$.

Interestingly, $\Delta P_{\max }$ generally deteriorates (decreases) at higher $Q_{\text {boil, }}$ especially for the small-capacity TPC configuration where it drops by about $2 \mathrm{mH}_{2} 0$, e.g. from $6.8 \mathrm{~m}$ at $10 \mathrm{~kW}$ to $4.8 \mathrm{~m}$ at $15 \mathrm{~kW}$ with $L_{\mathrm{PTL}}=5 \mathrm{~m}$. In the large-capacity TPC configuration the decrease in $\Delta P_{\max }$ is still evident, but this is more limited, dropping by about $0.5-1.0 \mathrm{mH}_{2} \mathrm{O}$, e.g. from $8.4 \mathrm{~m}$ at $10 \mathrm{~kW}$ to $7.5 \mathrm{~m}$ at $15 \mathrm{~kW}$ with $L_{\mathrm{PTL}}=5 \mathrm{~m}$. In summary, the large-capacity TPC with a longer PTL and at the lower $Q_{\text {boil }}$ setting has been demonstrated as being capable of operating with the maximum head differences across the circulator, which in the present experiments amounts to $8.4 \mathrm{mH}_{2} \mathrm{O}$.

Being a heat engine the TPC is expected to demonstrate a higher efficiency and a higher power output when the temperature difference across it is increased. Thus, its maximum head capability is also expected to increase at higher temperature differences $\Delta T_{\text {int }}$. Here, $\Delta T_{\text {int }}=T_{\text {HHX-fluid }}-T_{\text {CHX-fluid }}$ is the mean internal temperature difference experienced by the working fluid as it undergoes the thermodynamic cycle within the TPC, determined from temperature recordings such as those shown in Figure 5. Figure 9 (b) confirms that this is indeed the case for runs selected to be close to stalling at the highest heads, but not yet at fully stalled conditions. At full stall $\Delta T_{\text {int }}$ reaches a maximum value of about $15-20 \mathrm{~K}$, where it seems to saturate independently of $\Delta P_{\max }$. The average gradient in the 'high pressure' $\Delta P_{\max }$ per unit $\Delta T_{\text {int }}$ in Figure $9(\mathrm{~b})$ is $\sim 6 \mathrm{mH}_{2} \mathrm{O}$ per $7-8 \mathrm{~K}$, suggesting that a good rule of thumb for engineering design requires an increase in $\Delta T_{\text {int }}$ of the order of $1 \mathrm{~K}$ of a raising in $\Delta P_{\max }$ of $0.7 \mathrm{~m}$.

\subsection{Dynamic behaviour ( $f$ and $y$ )}

Thus far in the paper we have presented the measured pumping output of the TPC in its various configurations. In order to gain a better understating of the underlying processes that give rise to this pumping performance it is necessary to consider the operation of the TPC in more detail. The TPC is an oscillatory positivedisplacement machine and hence its operational frequency $f$ is a performance indicator of prime importance, as are the positive $y^{+}$and negative $y^{-}$displacement amplitudes with respect to the equilibrium vertical position (defined in Figure 1). These characteristics are the subject of the present section.

\subsubsection{Oscillation frequency}

The frequency $f$ of the TPC engine directly determines its output flow-rate, via the expression $U=\left(y^{+}-y^{-}\right) A_{p} f$, where $y^{+}$and $y^{-}$are the positive and negative displacement amplitudes of the liquid piston in the power cylinder (see Figure 1) and $A_{p}$ is the cross-sectional area of the power cylinder. Figure 10 shows the variation in the measured frequency $f$ of the TPC averaged over 10 experimental realisations per run (fixed conditions) as a function of $\Delta P$ for the four different TPC configurations and at various $Q_{\text {boil }}$ from 7 to $15 \mathrm{~kW}$.

The oscillation frequencies $f$ were found to be in the range $0.30 \pm 0.05 \mathrm{~Hz}$ in the small-capacity TPC configurations and $0.20 \pm 0.05 \mathrm{~Hz}$ in the large-capacity TPC configurations, decreasing slightly with increasing $\Delta P$ 
and almost independent of the setting of $\mathrm{Q}_{\text {boil }}$. The large-capacity TPC showed a very marginal decrease in $f$ with $\Delta P$, of the order of $0.01 \mathrm{~Hz}$ per $1 \mathrm{mH}_{2} \mathrm{O}$, whereas the large-capacity TPC had a more significant decrease of the order of $0.04 \mathrm{~Hz}$ per $1 \mathrm{mH}_{2} 0$. Changing the length of the PTL from $L_{\mathrm{PTL}}=2$ to $L_{\mathrm{PTL}}=5 \mathrm{~m}$ resulted in a decrease in $f$ by about $0.05 \mathrm{~Hz}$ when the small-capacity TPC configuration was tested. This finding is consistent with the explanation proposed earlier (in Section 4.1), that a longer PTL results in a greater liquid flow inertia in the load, which in turn would be expected to act so as to decrease the oscillation frequency of the TPC $[19,20]$. No consistent change in $f$ was observed when changing the PTL in the large-capacity TPC configuration. As with the flow-rate $U$, the maximum frequency $f_{0}$ is observed at the lowest head $\Delta P\left(\approx 0 \mathrm{mH}_{2} 0\right)$.

The frequencies at zero head $f_{0}$ are summarised in Table 4 . We note that the large-capacity TPC had a single $f_{0}$ of approximately $0.24 \mathrm{~Hz}$, independent of $Q_{\text {boil }}$ and $L_{\mathrm{PTL}}$, while the small-capacity TPC $f_{0}$ was slightly higher, ranging from $0.29 \mathrm{~Hz}$ (when the longer PTL was used) to $0.33 \mathrm{~Hz}$ (when the shorter PTL was used). For the same PTL, the increased liquid inertia and resistance that results from the longer length of piping in the large-capacity $\mathrm{CHX}$ would also be expected to lead to reduced $f[19,20]$, as indeed is the case. Lower frequencies are preferred for $a$ given flow-rate capability, as this minimises the use of the check valves and cyclic thermal stresses in the HHX (and also, CHX and elsewhere). At least in this regard, the large-capacity TPC configuration with its lower $f_{0}$, but also generally with its higher $U$ for a given $\Delta P$ (see Figure 7 ) is preferred.

\subsubsection{Oscillation amplitude $(y)$}

The output flow-rate of the TPC is also proportional to the difference $y^{+}-y^{-}$between the positive (suction/inwards flow) $y^{+}$and negative (discharge/outwards flow) and $y^{-}$displacement amplitudes of the liquid piston in the power cylinder (see Figure 1). Figures 11 and 12 (for the small-capacity TPC) and Figures 13 and 14 (for the large-capacity TPC) show the absolute measured values of the amplitudes as a function of flow-rate $U$ (a) and head rise across the TPC $\triangle P(b)$ for the various configurations. The same figures also contain the relative ratio of the amplitudes $y^{+} / y^{-}$as a function of flow-rate $U$ (c) and head rise $\Delta P$ (d). The common characteristic of these plots is that both $y^{+}$and $y^{-}$increase (in absolute magnitude) in experiments in which the flow-rate $U$ increases, whereas they decrease (in absolute magnitude) in experiments in which the head rise $\Delta P$ increases. This observation is consistent with the fact that the frequency $f$ does not vary significantly for operation at different conditions, such that the output flow-rate is a strong function of the two displacement amplitudes.

Proceeding further we observe that the ratio of suction to discharge amplitudes $y^{+} / y^{-}$typically increases with $U$ and decreases with head rise $\triangle P$. The small-capacity TPC exhibits a ratio that increases approximately linearly from zero and reaches a maximum value of $0.6-0.8$ at the highest $U$ and lowest $\Delta P$, with the upwards stroke being shorter than the downwards one. However, the large-capacity TPC has ratios exceeding unity, reaching values of 2.0 for $L_{\mathrm{PTL}}=2 \mathrm{~m}$ (Figure 13) or 1.5 for $L_{\mathrm{PTL}}=5 \mathrm{~m}$ (Figure 14). It is possible that the greater pumping capacity of the large-capacity TPC is connected to these higher ratios, with the balance between the evaporation and condensation ability of the $\mathrm{HHX}$ and $\mathrm{CHX}$ being the key determining factor in the relative negative and 
positive amplitudes exhibited by the TPC. Clearly, the sizing of the two heat exchangers is crucial in affecting this aspect of the device. The implication that results from this observation is that the improved capacity of the $\mathrm{CHX}$ (relative to the $\mathrm{HHX}$ ) in the present study is what has allowed the improvements observed in Configuration B. 


\section{CONCLUSIONS}

A thermally powered circulator based on the 'Non-Inertive-Feedback Thermofluidic Engine' (NIFTE), a twophase thermofluidic oscillator/heat engine technology, was constructed and operated successfully. The circulator was employed as a replacement for a central heating hot water circulator coupled to a domestic gas-fired boiler. Two heat exchanger designs and two power transmission lines were tested; the latter being a length of tube filled with liquid (in this case, water) that connects the circulator hot water flow circuit (pumping load) to its power cylinder, within which an oscillating liquid piston displaces liquid into and out or the circulating hot water circuit.

During regular operation the circulator demonstrated trends in which the mean pumped flow-rate decreased monotonically as the head applied across it increased, similarly to common electrical circulators. The maximum flow-rate measured was $850 \mathrm{~L} / \mathrm{hr}$, achieved with the high capacity combination of heat exchangers and a long power transmission line, whose increased inertia seems to offer performance improvements to the device. The maximum attainable (stalling) head measured was $8.4 \mathrm{mH}_{2} \mathrm{O}$, achieved with the same configuration. The maximum pumped flow-rates were attained at medium to high $10-15 \mathrm{~kW}$ boiler heat settings, and the maximum heads at medium $10-12 \mathrm{~kW}$ heat settings. Of this, the heat used by the circulator was about $3-5 \mathrm{~kW}$. Further, it was found that the increased introduction of heat into the circulator led generally to greater pumping flow-rates, until a certain level, after which the flow-rates indicated saturation. Interestingly, an enhanced heat flow-rate into the circulator also led eventually to a deterioration in the maximum pumping head capability. Conversely, the internal temperature difference across the working fluid (water/steam) within the circulator showed a positive correlation with the maximum head capability across the circulator, however, at the highest internal temperature differences of between 15 and $20^{\circ} \mathrm{C}$ a limit in the maximum head performance was observed.

The pumped flow-rates achieved can be contrasted to the flow-rate requirement of approximately $500-700$ $\mathrm{L} / \mathrm{hr}$ for a $10-15 \mathrm{~kW}$ central hearting boiler with $60{ }^{\circ} \mathrm{C}$ supply and $40{ }^{\circ} \mathrm{C}$ hot water return temperature, respectively. This comparison implies that the prototype is capable of achieving a realistic pumping performance for this application, though it ought to be pointed out that at the higher heads that would experienced in real central heating flow circuits the flow-rate output of the circulator deteriorates.

The oscillating circulator was shown to have an operational frequency that was not strongly affected by the conditions, but that was set by the circulator configuration. It was found to be approximately $0.29-0.33 \mathrm{~Hz}$ for a circulator with short heat exchanger tubes, and $0.24 \mathrm{~Hz}$ for an alternate configuration with a longer length of exchanger tubes. In addition, a further increase in the length of the power transmission line was shown to lead to lower operational frequencies, but slightly improved head and flow-rate performance. The latter conclusion is in good agreement with predictions from simple dynamic models of the circulator [18-20] that preceded the present study. Thus, it was found that the pumping capacity of the circulator was mostly determined by the oscillating liquid amplitudes in the power cylinder that defined the positive displacement amplitude of the liquid piston into and out of the hot water circuit. The best circulator configuration was associated with lower operation frequencies and relatively large ratios of suction to discharge displacement. It is concluded that an improved 
circulator should result from an increased sizing of both the hot and cold heat exchangers to improve heat exchange capacity, but also from the careful balancing between the sizes of the two heat exchangers. 


\section{ACKNOWLEDGEMENT}

CNM would like to thank Thomas Smith without whom this work would not have been possible. The experiments were done during AG's visit to Imperial College London under an undergraduate visiting research student scheme.

\section{REFERENCES}

[1] Markides CN. The role of pumped and waste heat technologies in a high-efficiency sustainable energy future for the UK. Applied Thermal Engineering 2012; in press.

[2] Bisio G, Rubatto G. Sondhauss and Rijke oscillations-thermodynamic analysis, possible applications and analogies. Energy 1999;24:117-131.

[3] Wheatley J, Hofler T, Swift G, Migliori A. An intrinsically irreversible thermoacoustic heat engine. Journal of the Acoustical Society of America 1983;74:153-170.

[4] Wheatley J, Hofler T, Swift G, Migliori A. Experiments with an intrinsically irreversible acoustic heat engine. Physical Review Letters 1983;50:499-502.

[5] Backhaus S, Swift G. A thermoacoustic-Stirling heat engine: Detailed study. Journal of the Acoustical Society of America 2000;107:3148-3166.

[6] Ceperley PH. A pistonless Stirling engine-the traveling wave heat engine. Journal of the Acoustical Society of America 1979;66:1508-1513.

[7] Sun D, Qiu L, Zhang W, Yan W, Chen G. Investigation on traveling wave thermoacoustic heat engine with high pressure amplitude. Energy Conversion and Management 2005;46:281-291.

[8] Qiu L, Sun D, Tan Y, Yan W, Chen P, Zhao L, Chen G. Effect of pressure disturbance on onset processes in thermoacoustic engine. Energy Conversion and Management 2006;47:1383-1390.

[9] Redlich RW, Berchowitz DM. Linear dynamics of free-piston Stirling engines. Proceedings of the Institution of Mechanical Engineers.Part A: Journal of Power and Energy 1985;199:203-213.

[10] Dai W, Luo E, Zhang Y, Ling H. Detailed study of a traveling wave thermoacoustic refrigerator driven by a traveling wave thermoacoustic engine. Journal of the Acoustical Society of America 2006;119:2686-2692.

[11] Luo E, Hu J, Dai W, Chen Y. An acoustical pump capable of significantly increasing pressure ratio of thermoacoustic heat engines. Chinese Science Bulletin 2006;51:1014.

[12] Tang K, Lei T, Jin T, Lin XG, Xu ZZ. A standing-wave thermoacoustic engine with gas-liquid coupling oscillation. Applied Physics Letters 2009;94:254101.

[13] West CD. Dynamic analysis of the fluidyne. In: Proceedings of the 18th Intersociety Energy Conversion Engineering Conference (IECEC 1983), Orlando, FL; 1983, p. 779-784.

[14] Howard DL. Liquid piston heat engine. Patent 1993;F02G 104.

[15] West CD. Stirling engines with controlled evaporation of a two-phase two-component working fluid. In: Proceedings of the 18th Intersociety Energy Conversion Engineering Conference (IECEC 1983), Orlando, FL; 1983, p. 914-917.

[16] Gertsmann J. Diesel-fired self-pumping water heater. Technical Report 1994;NATICKITR-94/025. 
[17] Smith TCB. Thermally driven oscillations in dynamic applications. PhD thesis. Cambridge: University of Cambridge; 2006.

[18] Markides CN, Smith TCB. A dynamic model for the efficiency optimization of an oscillatory low grade heat engine. Energy 2011;36:6967-80.

[19] Solanki R, Galindo A, Markides CN. Dynamic modelling of a two-phase thermofluidic oscillator for efficient low grade heat utilization: Effect of fluid inertia. Applied Energy 2012; 89:156-63.

[20] Solanki R, Galindo A, Markides CN. The role of heat exchange on the behaviour of a two-phase thermofluidic oscillator. Applied Thermal Engineering 2012; in press.

[21] Mathie R, Markides C. Unsteady 1D thermal conduction in finite solids, and composite bodies. In: Proceedings of the 11th UK Heat Transfer Conference (UKHTC 2009), Queen Mary, London; 2009, p. 1-12.

[22] Mathie R, Smith T, Markides C. Heat transfer-thermodynamic cycle interactions in the Non-Inertive Feedback Thermofluidic Engine. Thermodynamics 2009 Conference, Imperial College, London; 2009. 


\section{FIGURE CAPTIONS}

Figure 1. Schematic of the apparatus and measurement facility. Showing the flow-rate measurement in the central heating $(\mathrm{CH})$ circuit $U_{\mathrm{e}}$ and the flame in the boiler burner (with heat setting $Q_{\text {boil }}$ ) from which heat $Q_{\mathrm{CH}}$ is supplied to the $\mathrm{CH}$ circuit and heat $Q_{\mathrm{HHX}}$ to the hot heat exchanger $(\mathrm{HHX})$ of the thermally powered circulator (TPC). Temperatures TC-1 and TC-2 were sampled continuously, while T-1 and T-2 were recorded from displays at steady state.

Figure 2. Pressure reservoirs and measurement details.

Figure 3. Pressure difference measured across the TPC during (a) low-load, normal steady-state operation and (b) stalling due to pressure at high load.

Figure 4. Temperature on the (a) HHX walls and (b) CHX walls, during normal steady-state operation.

Figure 5. Temperature recorded by (a) thermocouple TC-1, i.e. of the steam being generated in the HHX and flowing into the top of the displacement cylinder and (b) thermocouple TC-2 placed inside the CHX near the HHX$\mathrm{CHX}$ connection, during normal steady-state operation.

Figure 6. Pumping action with beating at two distinct frequencies.

Figure 7. Configuration A (small-capacity TPC) with (a) short $L_{\mathrm{PTL}}=2 \mathrm{~m}$ and (b) long $L_{\mathrm{PTL}}=5 \mathrm{~m}$. Legends indicating the various settings for $Q_{\text {boil }}$ at which the $U$ against $\Delta P$ results were obtained. Configuration B (large capacity HHX$\mathrm{CHX}$ ) with (a) short $L_{\mathrm{PTL}}=2 \mathrm{~m}$ and (b) long $L_{\mathrm{PTL}}=5 \mathrm{~m}$. Legends indicating the various settings for $Q_{\text {boil }}$ at which the $U$ against $\Delta P$ results were obtained.

Figure 8. Maximum flow-rate $U_{0}$ at zero head for the various configurations as a function of $Q_{\mathrm{HHx}}$.

Figure 9. Stalling pressure $\Delta P_{\max }$ for the various configurations as a function of (a) $Q_{H H x}$ and (b) $\Delta T_{\text {int }}$. 
Figure 10. Oscillation frequency $f$ as a function of pressure difference $\Delta P$ for (a) Configuration A (small-capacity TPC) and (b) Configuration B (large-capacity TPC), with both the short $L_{\mathrm{PTL}}=2 \mathrm{~m}$ and long $L_{\mathrm{PTL}}=5 \mathrm{~m}$.

Figure 11. Oscillation amplitudes $y^{+}$and $y^{-}$, and their ratio $y^{+} / y^{-}$, as a function of $(a, c)$ the mean flow-rate $U$ and (b, d) the pressure difference $\Delta P$, for Configuration A (small-capacity TPC) with the short $L_{P T L}=2 \mathrm{~m}$.

Figure 12. Oscillation amplitudes $y^{+}$and $y^{-}$, and their ratio $y^{+} / y^{-}$, as a function of $(\mathrm{a}, \mathrm{c})$ the mean flow-rate $U$ and (b, d) the pressure difference $\Delta P$, for Configuration A (small-capacity TPC) with the long $L_{\mathrm{PTL}}=5 \mathrm{~m}$.

Figure 13. Oscillation amplitudes $y^{+}$and $y^{-}$, and their ratio $y^{+} / y^{-}$, as a function of $(a, c)$ the mean flow-rate $U$ and (b, d) the pressure difference $\Delta P$, for Configuration B (large-capacity TPC) with the short $L_{\mathrm{PTL}}=2 \mathrm{~m}$.

Figure 14. Oscillation amplitudes $y^{+}$and $y^{-}$, and their ratio $y^{+} / y^{-}$, as a function of $(a, c)$ the mean flow-rate $U$ and (b, d) the pressure difference $\Delta P$, for Configuration B (large-capacity TPC) with the long $L_{P T L}=5 \mathrm{~m}$. 


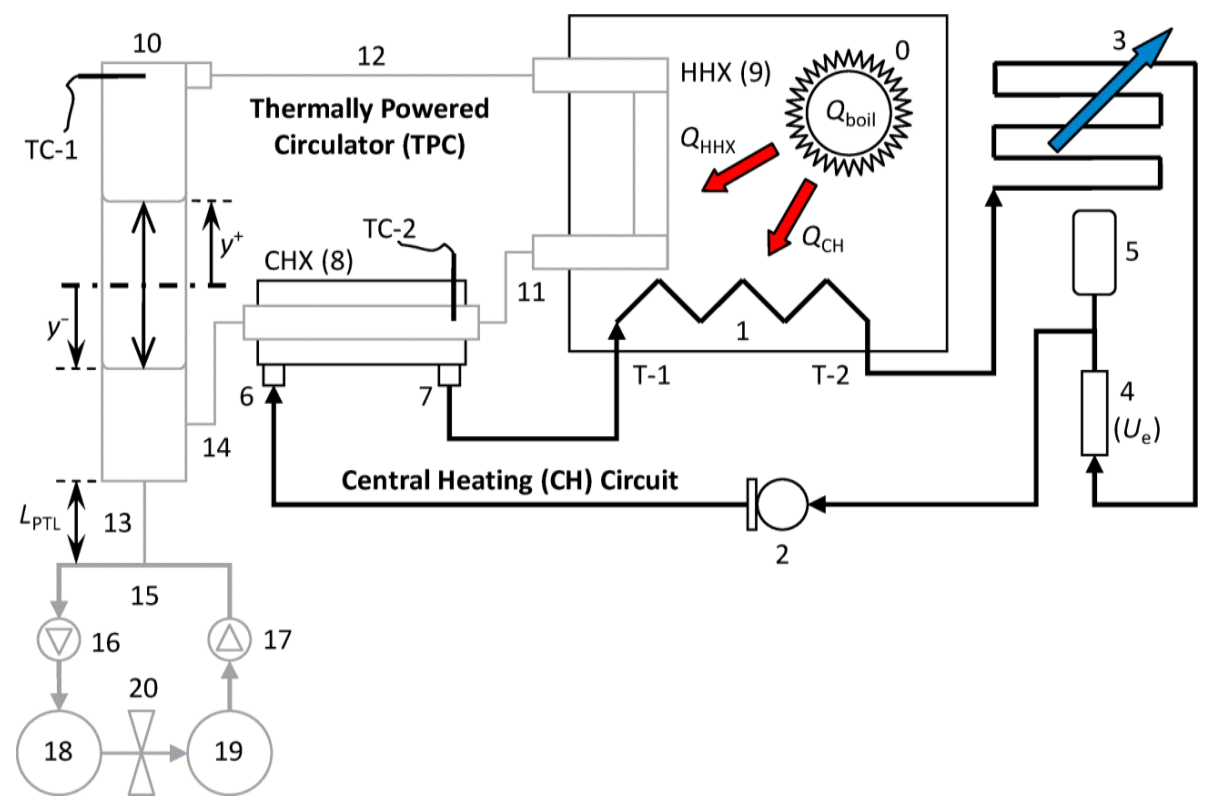

Figure 1. Schematic of the apparatus and measurement facility. Showing the flow-rate measurement in the central heating $(\mathrm{CH})$ circuit $U_{\mathrm{e}}$ and the flame in the boiler burner (with heat setting $Q_{\text {boil }}$ ) from which heat $Q_{\mathrm{CH}}$ is supplied to the $\mathrm{CH}$ circuit and heat $Q_{\mathrm{HHX}}$ to the hot heat exchanger $(\mathrm{HHX})$ of the thermally powered circulator (TPC). Temperatures TC-1 and TC-2 were sampled continuously, while T-1 and T-2 were recorded from displays at steady state. 


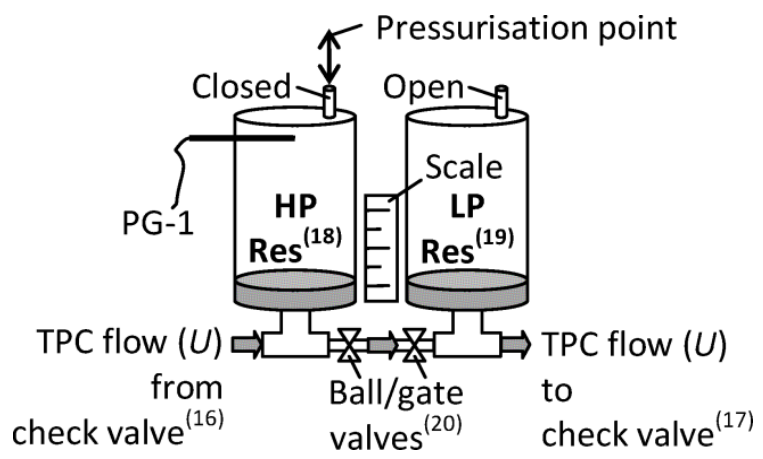

Figure 2. Pressure reservoirs and measurement details. 


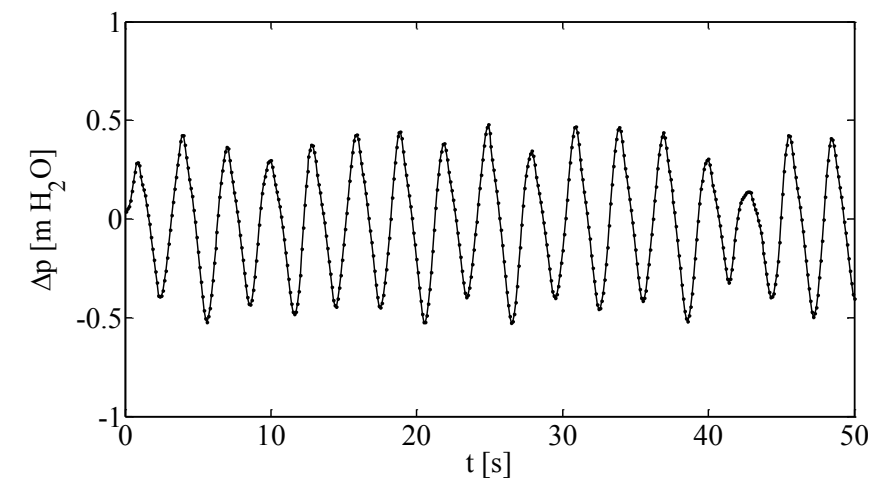

(a)

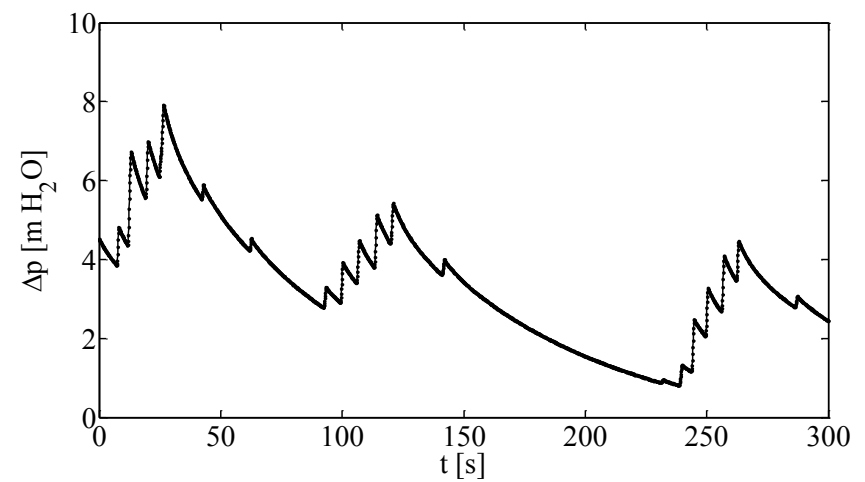

(b)

Figure 3. Pressure difference measured across the TPC during (a) low-load, normal steady-state operation and (b) stalling due to pressure at high load. 


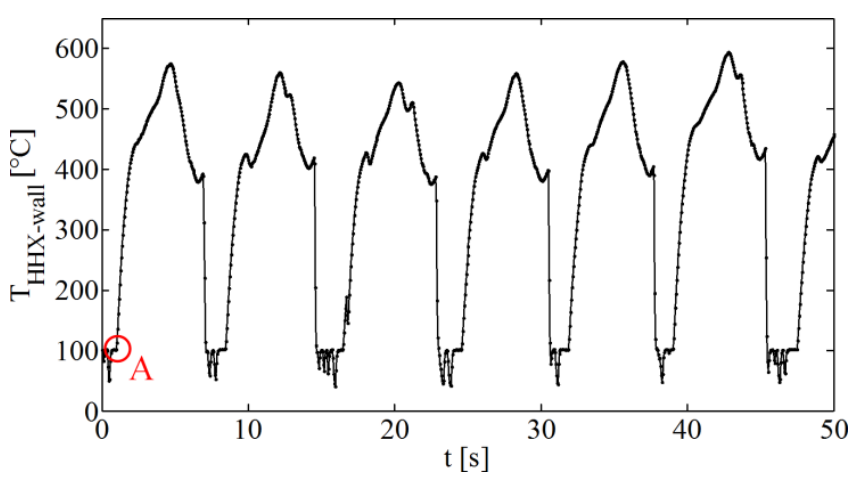

(a)

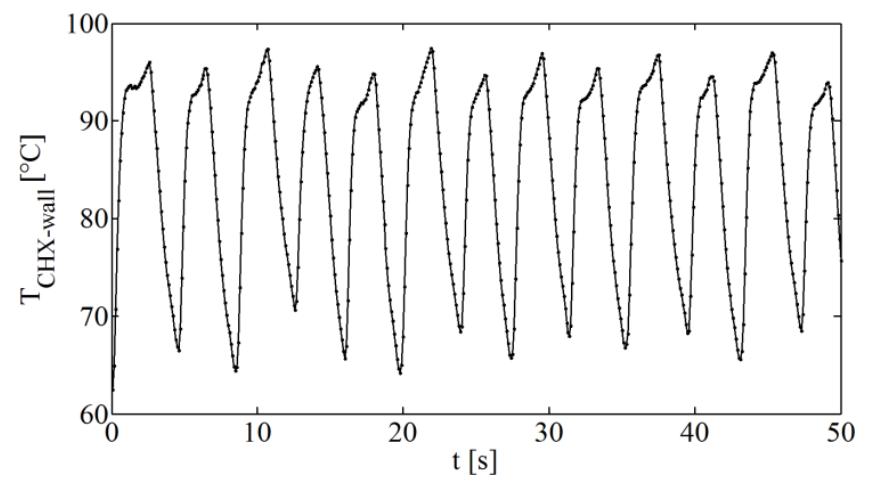

(b)

Figure 4. Temperature on the (a) HHX walls and (b) $\mathrm{CHX}$ walls, during normal steady-state operation. 


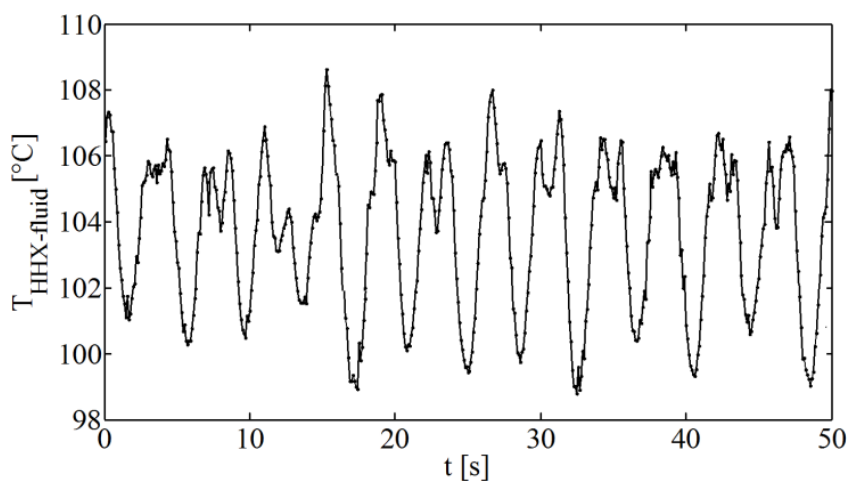

(a)

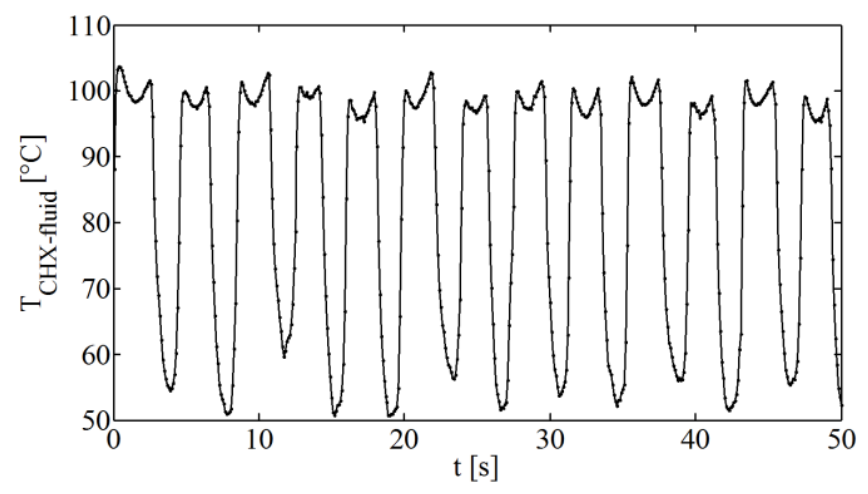

(b)

Figure 5. Temperature recorded by (a) thermocouple TC-1, i.e. of the steam being generated in the HHX and flowing into the top of the displacement cylinder and (b) thermocouple TC-2 placed inside the CHX near the HHX$\mathrm{CHX}$ connection, during normal steady-state operation. 


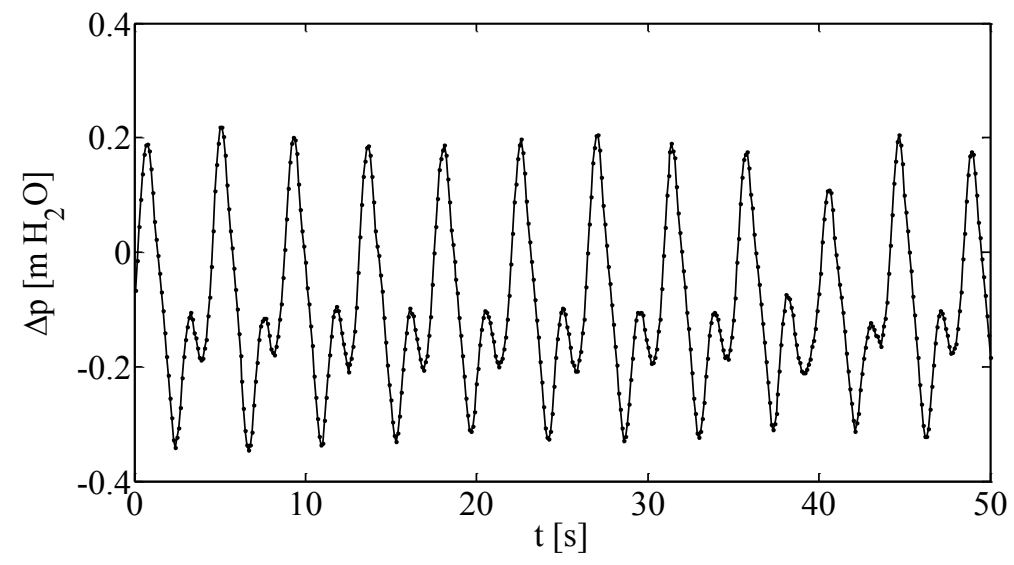

Figure 6. Pumping action with beating at two distinct frequencies. 


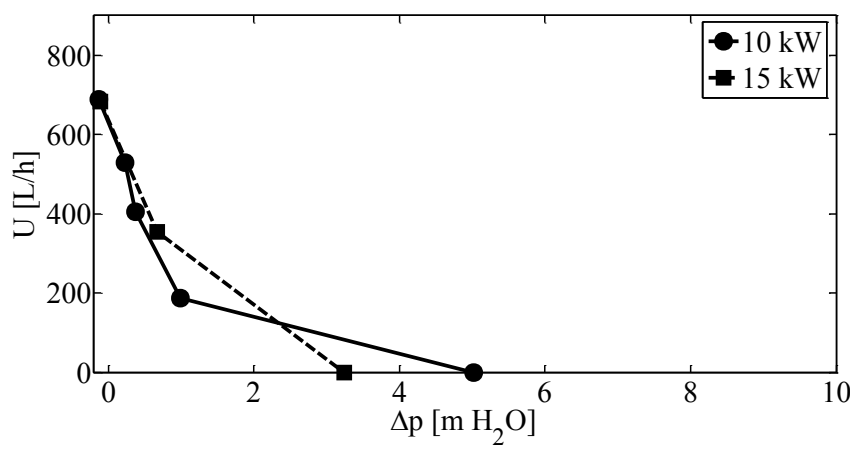

(a)

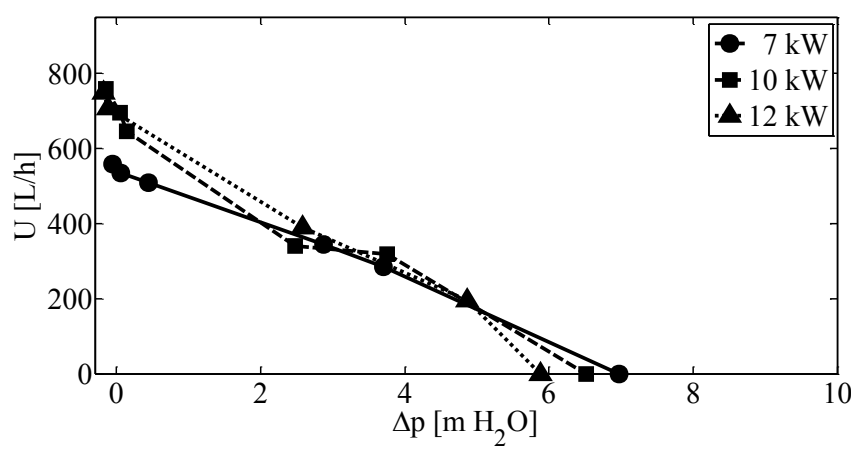

(c)

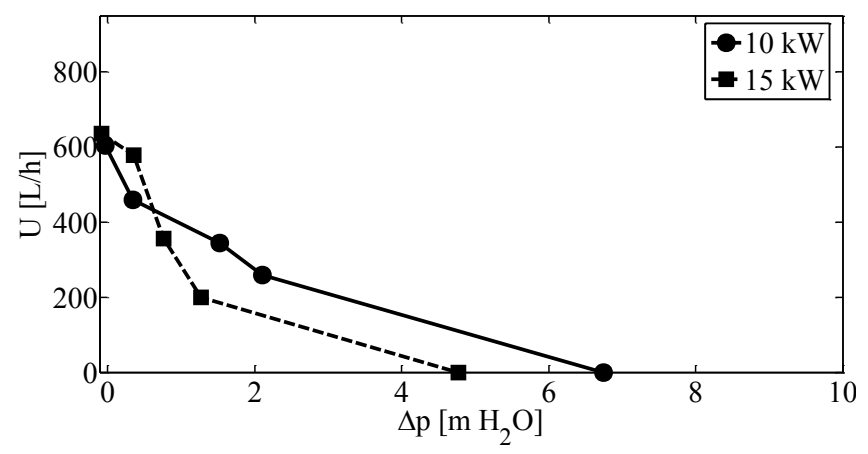

(b)

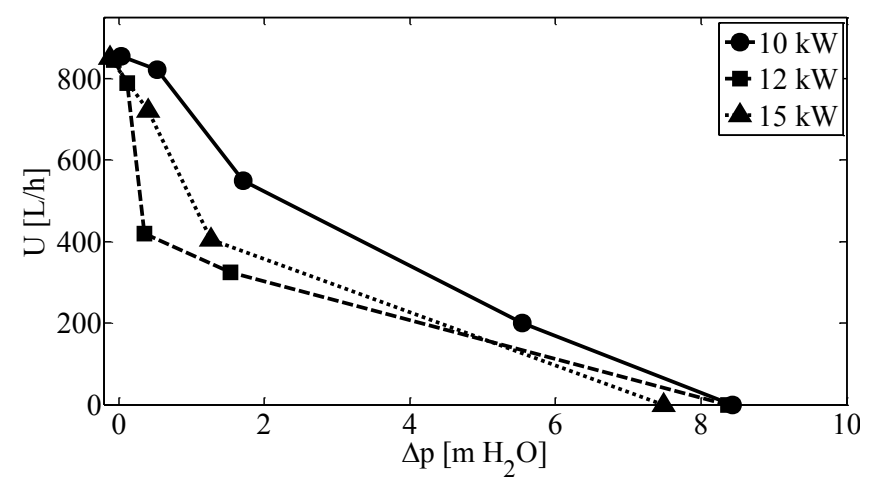

(d)

Figure 7. Configuration A (small-capacity TPC) with (a) short $L_{\mathrm{PTL}}=2 \mathrm{~m}$ and (b) long $L_{\mathrm{PTL}}=5 \mathrm{~m}$. Legends indicating the various settings for $Q_{\text {boil }}$ at which the $U$ against $\Delta P$ results were obtained. Configuration B (large capacity $H H X-$ $\mathrm{CHX}$ ) with (a) short $L_{\mathrm{PTL}}=2 \mathrm{~m}$ and (b) long $L_{\mathrm{PTL}}=5 \mathrm{~m}$. Legends indicating the various settings for $Q_{\text {boil }}$ at which the $U$ against $\Delta P$ results were obtained. 


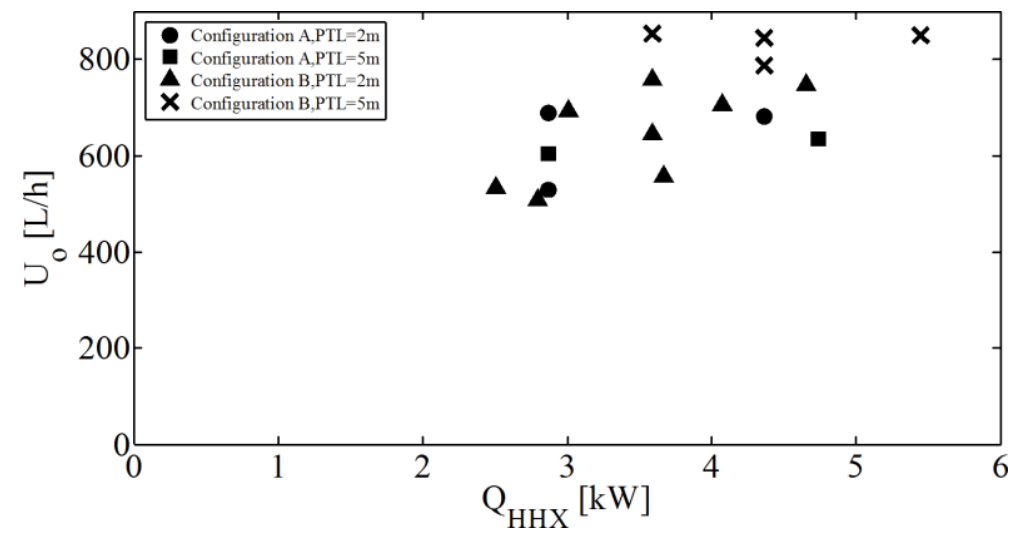

Figure 8. Maximum flow-rate $U_{0}$ at zero head for the various configurations as a function of $Q_{H H x}$. 


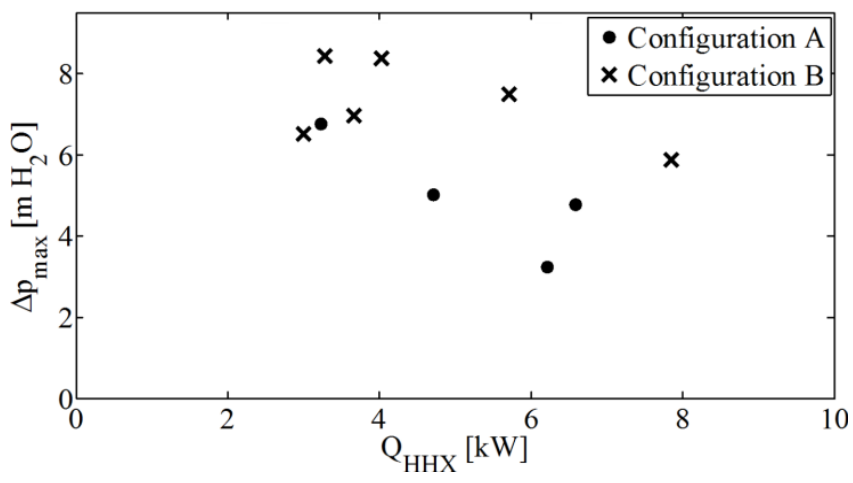

(a)

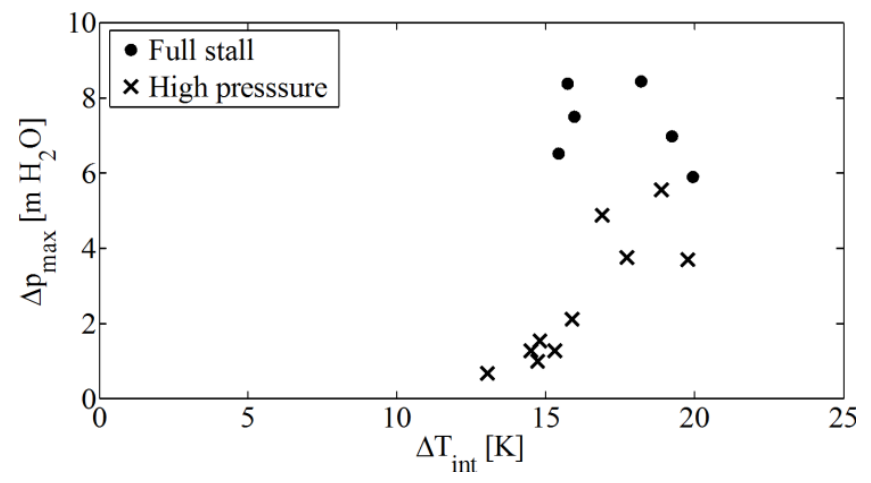

(b)

Figure 9. Stalling pressure $\Delta P_{\max }$ for the various configurations as a function of (a) $Q_{H H x}$ and (b) $\Delta T_{\text {int. }}$. 


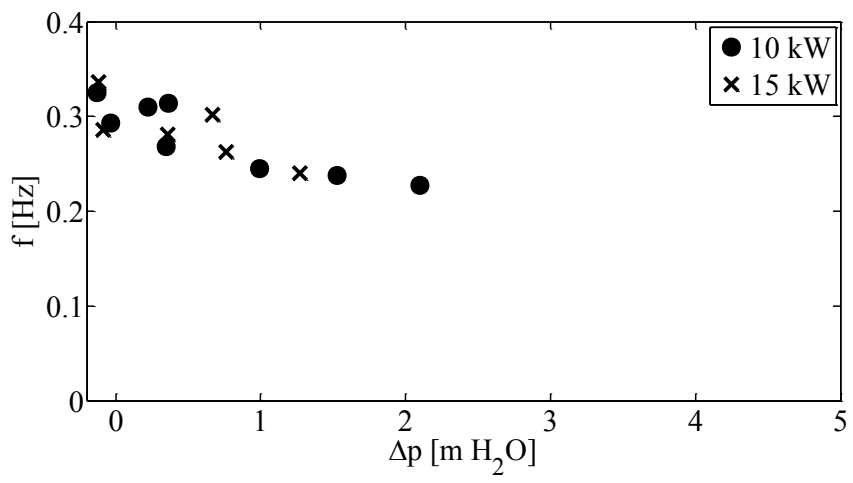

(a)

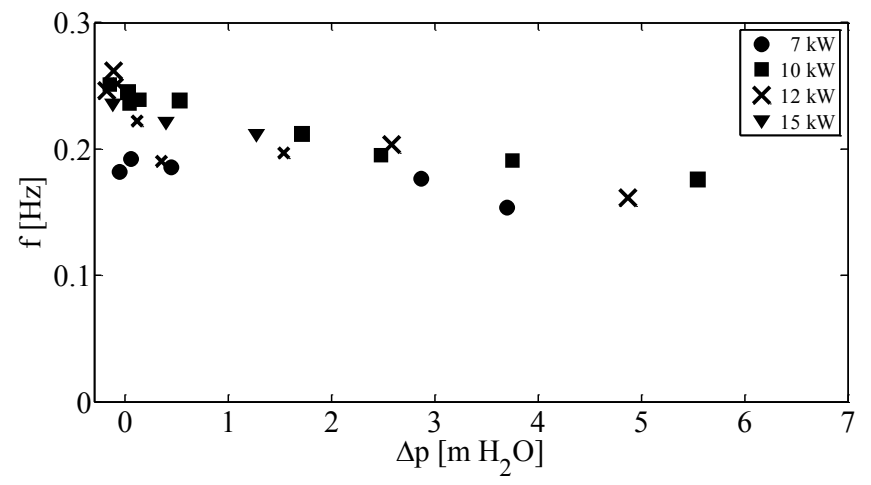

(b)

Figure 10. Oscillation frequency $f$ as a function of pressure difference $\Delta P$ for (a) Configuration A (small-capacity TPC) and (b) Configuration B (large-capacity TPC), with both the short $L_{\mathrm{PTL}}=2 \mathrm{~m}$ and long $L_{\mathrm{PTL}}=5 \mathrm{~m}$. 


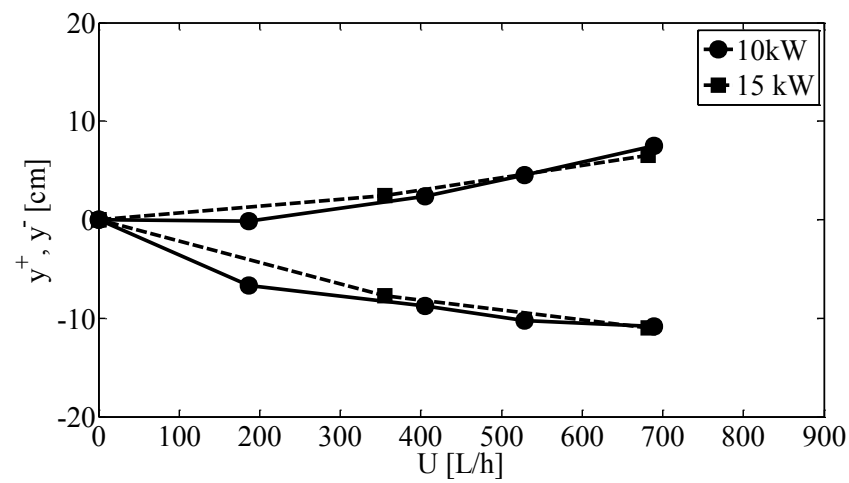

(a)

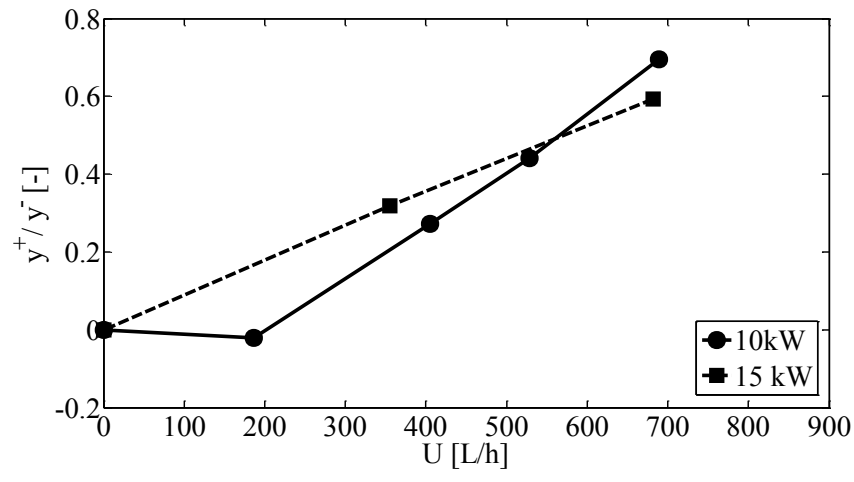

(c)

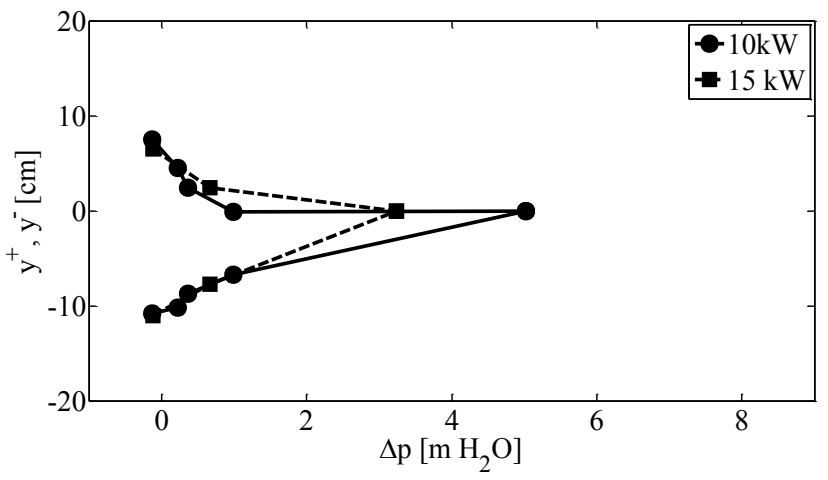

(b)

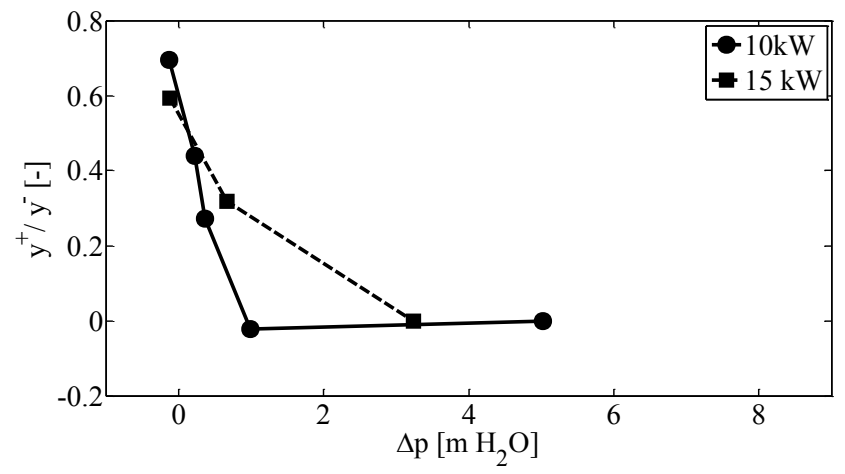

(d)

Figure 11. Oscillation amplitudes $y^{+}$and $y^{-}$, and their ratio $y^{+} / y^{-}$, as a function of $(a, c)$ the mean flow-rate $U$ and (b, d) the pressure difference $\Delta P$, for Configuration A (small-capacity TPC) with the short $L_{\mathrm{PTL}}=2 \mathrm{~m}$. 


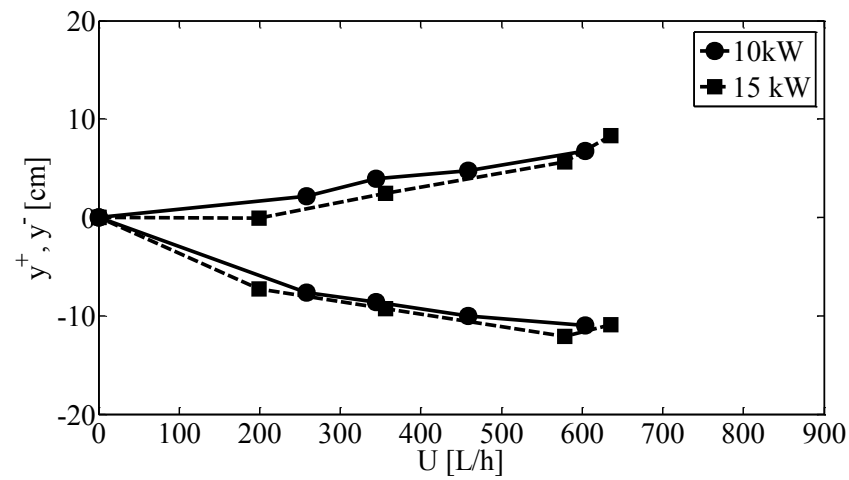

(a)

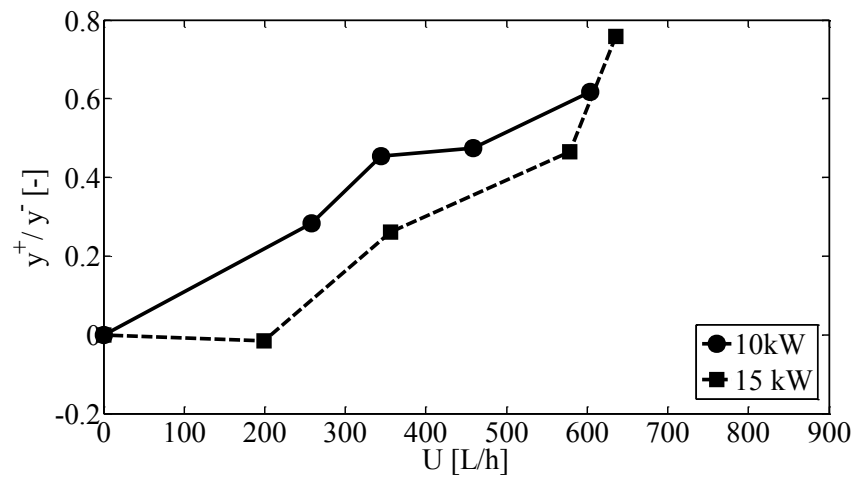

(c)

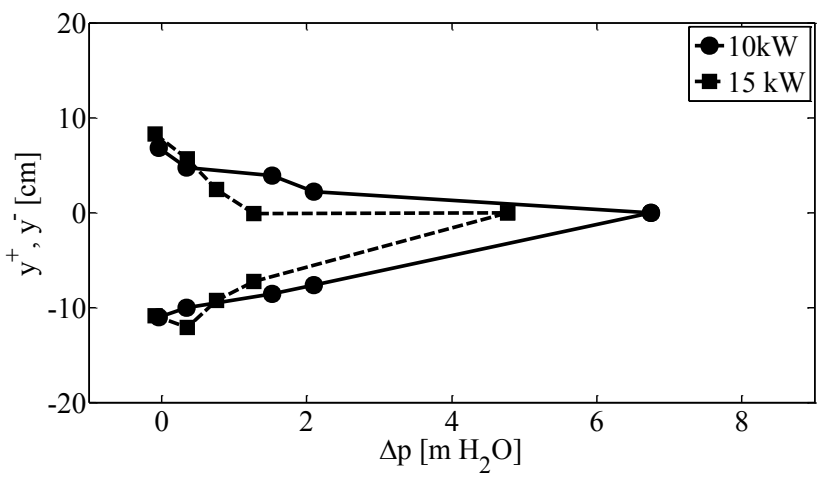

(b)

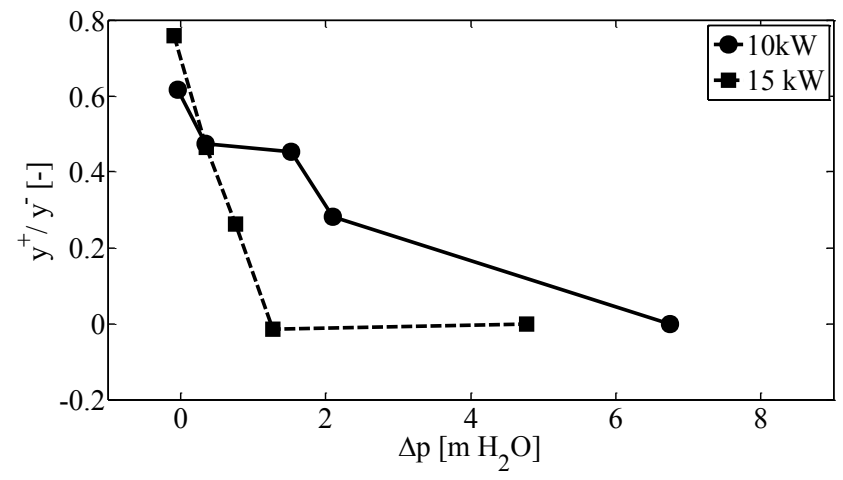

(d)

Figure 12. Oscillation amplitudes $y^{+}$and $y^{-}$, and their ratio $y^{+} / y^{-}$, as a function of $(a, c)$ the mean flow-rate $U$ and (b, d) the pressure difference $\Delta P$, for Configuration A (small-capacity TPC) with the long $L_{P T L}=5 \mathrm{~m}$. 


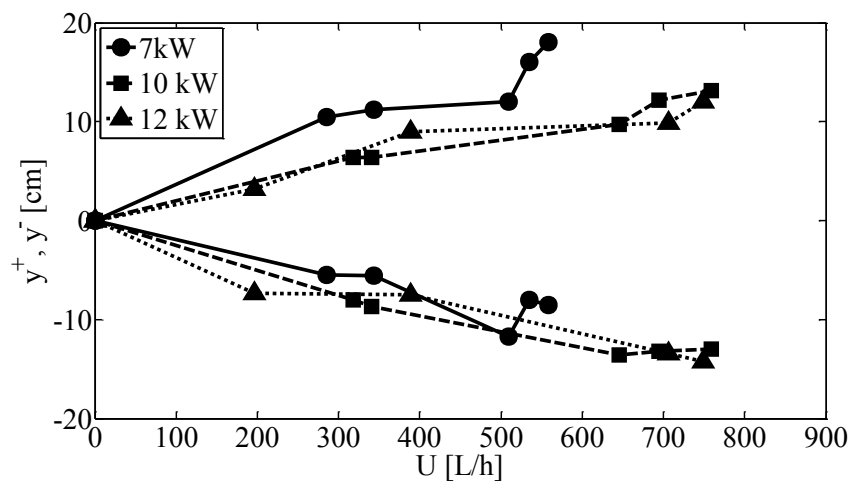

(a)

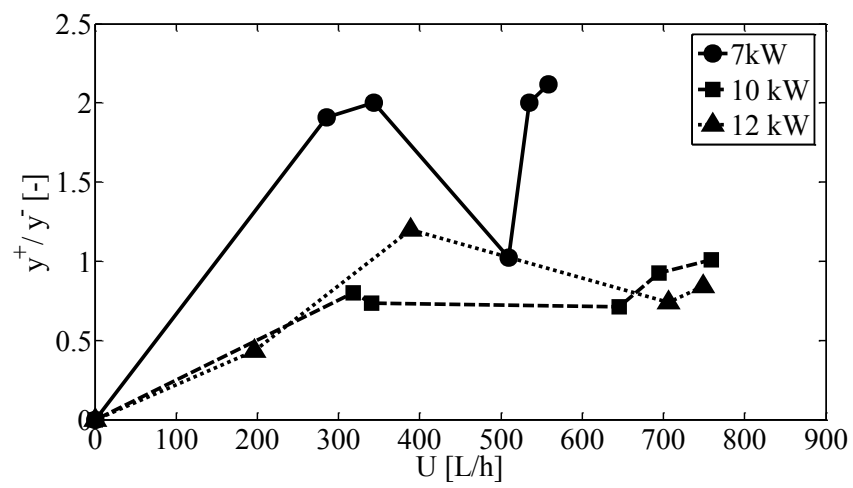

(c)

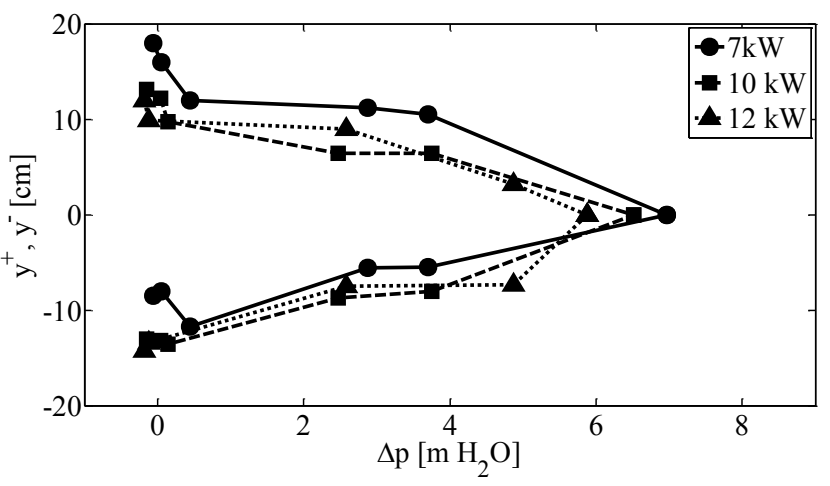

(b)

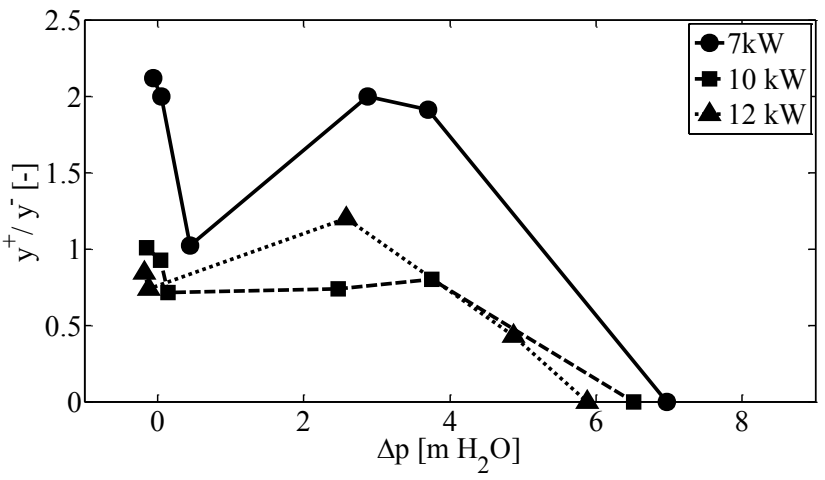

(d)

Figure 13. Oscillation amplitudes $y^{+}$and $y^{-}$, and their ratio $y^{+} / y^{-}$, as a function of $(a, c)$ the mean flow-rate $U$ and (b, d) the pressure difference $\Delta P$, for Configuration $B$ (large-capacity TPC) with the short $L_{\mathrm{PTL}}=2 \mathrm{~m}$. 


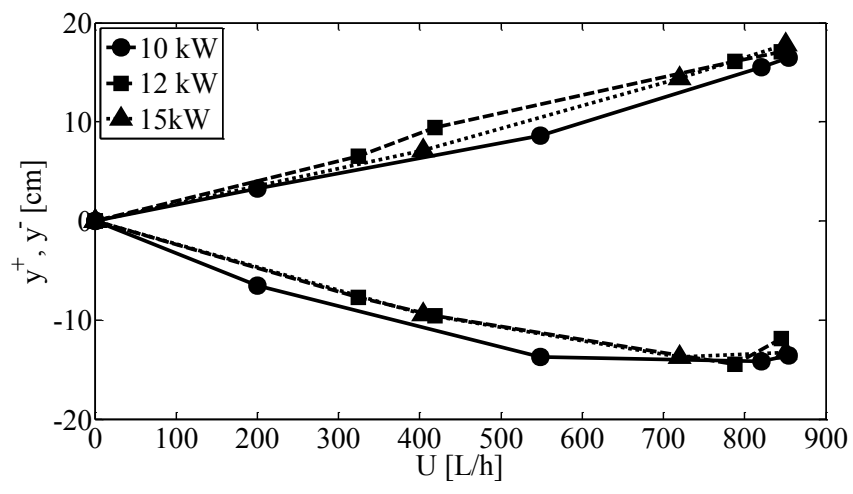

(a)

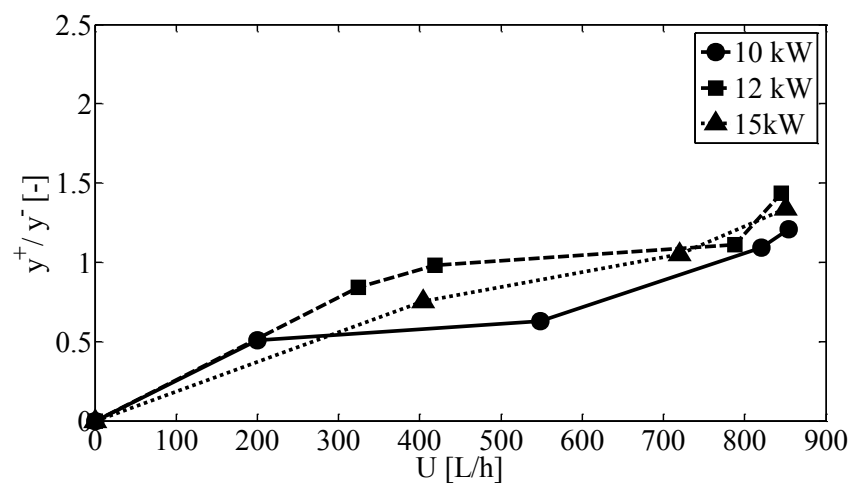

(c)

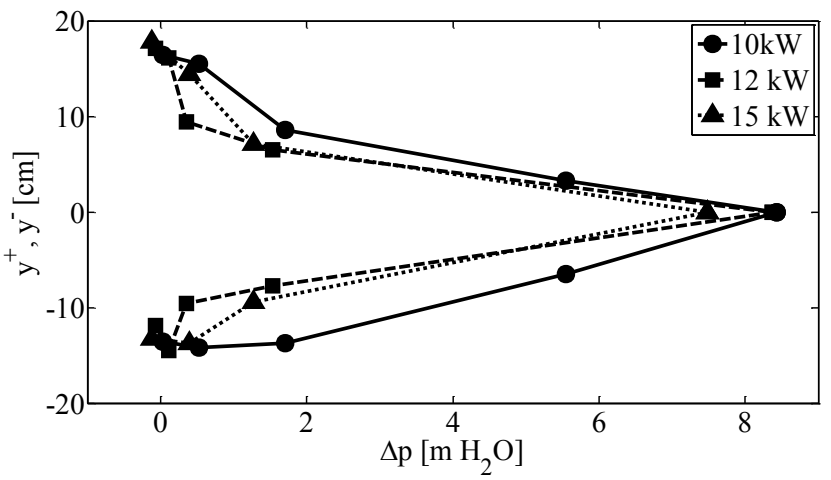

(b)

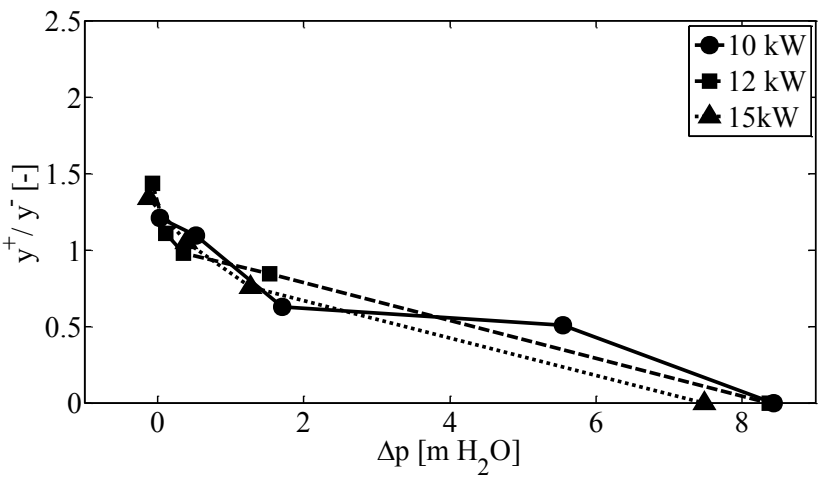

(d)

Figure 14. Oscillation amplitudes $y^{+}$and $y^{-}$, and their ratio $y^{+} / y^{-}$, as a function of $(a, c)$ the mean flow-rate $U$ and (b, d) the pressure difference $\Delta P$, for Configuration B (large-capacity TPC) with the long $L_{P T L}=5 \mathrm{~m}$. 
Table 1: $Q_{\mathrm{HHX}}$ in $\mathrm{kW}$ at the various $Q_{\mathrm{boil}}$ for different heat exchanger/thermally powered circulator configurations.

\begin{tabular}{l|c|c|c|c|c}
\hline \multicolumn{2}{c|}{$Q_{\mathrm{HHX}}(\mathrm{kW})$} & \multicolumn{4}{c}{$Q_{\text {boil }}(\mathrm{kW})$} \\
\hline $\begin{array}{l}\text { HHX-CHX/TPC } \\
\text { Configuration }\end{array}$ & $\begin{array}{c}L_{\mathrm{PTL}} \\
(\mathrm{m})\end{array}$ & 7 & 10 & 12 & 15 \\
\hline \multirow{2}{*}{ Small-capacity } & 2 & - & $2.1-2.9$ & - & $4.4-4.7$ \\
\cline { 2 - 6 } & 5 & - & $2.5-3.2$ & - & $4.0-4.7$ \\
\hline \multirow{2}{*}{ Large-capacity } & 2 & $2.3-3.5$ & $3.0-3.6$ & $3.2-5.2$ & - \\
\cline { 2 - 6 } & 5 & - & $2.7-3.9$ & $4.1-4.7$ & $4.0-5.5$ \\
\hline
\end{tabular}


Table 2: Flow-rate $U_{0}$ in $\mathrm{L} / \mathrm{hr}$ at zero head $\Delta P=0 \mathrm{~m}$ for the various pump configurations and $Q_{\text {boil }}$.

\begin{tabular}{l|c|c|c|c|c}
\hline \multicolumn{1}{c|}{$U_{\mathbf{0}}(\mathrm{L} / \mathrm{hr})$ in Configuration } & \multicolumn{4}{|c}{$Q_{\text {boil }}(\mathrm{kW})$} \\
\hline $\begin{array}{l}\text { HHX-CHX/TPC } \\
\text { Configuration }\end{array}$ & $\begin{array}{c}\boldsymbol{L}_{\mathrm{PTL}} \\
(\mathbf{m})\end{array}$ & $\mathbf{7}$ & $\mathbf{1 0}$ & $\mathbf{1 2}$ & 15 \\
\hline \multirow{2}{*}{ A) Small-capacity } & 2 & - & 650 & - & 650 \\
\cline { 2 - 6 } & 5 & - & 600 & - & 620 \\
\hline \multirow{2}{*}{ B) Large-capacity } & 2 & 550 & 720 & 720 & - \\
\cline { 2 - 6 } & 5 & - & 850 & 850 & 850 \\
\hline
\end{tabular}


Table 3: Stalling head $\Delta P_{\max }$ in $\mathrm{m}$ for the various configurations and $Q_{\text {boil }}$.

\begin{tabular}{l|c|c|c|c|c}
\hline \multicolumn{1}{c|}{$\Delta \boldsymbol{P}_{\max }(\mathrm{m})$ in Configuration } & \multicolumn{4}{|c}{$\boldsymbol{Q}_{\text {boil }}(\mathrm{kW})$} \\
\hline $\begin{array}{l}\text { HHX-CHX/TPC } \\
\text { Configuration }\end{array}$ & $\begin{array}{c}\boldsymbol{L}_{\mathrm{PTL}} \\
(\mathbf{m})\end{array}$ & $\mathbf{7}$ & $\mathbf{1 0}$ & $\mathbf{1 2}$ & $\mathbf{1 5}$ \\
\hline \multirow{2}{*}{ A) Small-capacity } & 2 & - & 5.0 & - & 3.2 \\
\cline { 2 - 6 } & 5 & - & 6.8 & - & 4.8 \\
\hline \multirow{2}{*}{ B) Large-capacity } & 2 & 7.0 & 6.5 & 5.9 & - \\
\cline { 2 - 6 } & 5 & - & 8.4 & 8.4 & 7.5 \\
\hline
\end{tabular}


Table 4: Frequency at zero head $f_{0}$ in $\mathrm{Hz}$ for the various configurations and $Q_{\text {boil }}$.

\begin{tabular}{|c|c|c|c|c|}
\hline \multicolumn{2}{|c|}{$f_{0}(\mathrm{~Hz})$ in Configuration } & \multicolumn{3}{|c|}{$Q_{\text {boil }}(k W)$} \\
\hline $\begin{array}{l}\text { HHX-CHX/TPC } \\
\text { Configuration }\end{array}$ & $\begin{array}{l}L_{\mathrm{PTL}} \\
(\mathrm{m})\end{array}$ & 10 & 12 & 15 \\
\hline \multirow{2}{*}{ A) Small-capacity } & 2 & \multicolumn{3}{|c|}{$0.33 \pm 0.01$} \\
\hline & 5 & \multicolumn{3}{|c|}{$0.29 \pm 0.01$} \\
\hline \multirow{2}{*}{ B) Large-capacity } & 2 & \multirow{2}{*}{\multicolumn{3}{|c|}{$0.24 \pm 0.01$}} \\
\hline & 5 & & & \\
\hline
\end{tabular}

